\title{
Bioreactor control systems in the biopharmaceutical industry: a critical perspective
}

\author{
Sagnik Mitra ${ }^{1} \cdot$ Ganti S. Murthy ${ }^{1}$
}

Received: 31 May 2021 / Revised: 27 July 2021 / Accepted: 28 July 2021 / Published online: 5 August 2021

(c) Jiangnan University 2021

\begin{abstract}
Industrial-scale bioprocessing underpins much of the production of pharmaceuticals, nutraceuticals, food, and beverage processing industries of the modern world. The profitability of these processes increasingly leverages the economies of scale and scope that are critically dependent on the product yields, titers, and productivity. Most of the processes are controlled using classical control approaches and represent over $90 \%$ of the industrial controls used in bioprocessing industries. However, with the advances in the production processes, especially in the biopharmaceutical and nutraceutical industries, monitoring and control of bioprocesses such as fermentations with GMO organisms, and downstream processing has become increasingly complex and the inadequacies of the classical and some of the modern control systems techniques is becoming apparent. Therefore, with increasing research complexity, nonlinearity, and digitization in process, there has been a critical need for advanced process control that is more effective, and easier process intensification and product yield (both by quality and quantity) can be achieved. In this review, industrial aspects of a process and automation along with various commercial control strategies have been extensively discussed to give an insight into the future prospects of industrial development and possible new strategies for process control and automation with a special focus on the biopharmaceutical industry.
\end{abstract}

Keywords Bioreactor control systems · Digitization · Advanced process control · Industrial automation · Single-use technology $\cdot$ Biopharmaceuticals

\begin{tabular}{|c|c|c|c|}
\hline \multicolumn{2}{|c|}{ Abbreviations } & CQA & Critical quality attributes \\
\hline $\mathrm{A} / \mathrm{D}$ & Analog to digital & $\mathrm{D}$ & Derivative \\
\hline ANN & Artificial neural network & $\mathrm{D} / \mathrm{A}$ & Digital to analog \\
\hline APC & Advanced process control & DCS & Distributed control system \\
\hline API & Active pharmaceutical ingredient & $\mathrm{DO}$ & Dissolved oxygen \\
\hline ATF & Alternating tangential flow & DoE & Design of experiment \\
\hline BPSA & Bio-process System Alliance & DT & Digital twin \\
\hline CAGR & Compound annual growth rate & ERP & Enterprise resource planning \\
\hline CAPEX & Capital expenditure & $\mathrm{EPC}$ & Engineering procurement and construction \\
\hline \multirow[t]{2}{*}{ CDMO } & Contract Development and Manufacturing & FBA & Flux balance analysis \\
\hline & Organization & FDA & Food and Drug Administration \\
\hline CFD & Computational fluid dynamics & FET & Field effect transistor \\
\hline $\mathrm{CMO}$ & Contract Manufacturing Organization & FEP & Fluorinated ethylene polymer \\
\hline $\mathrm{COM}$ & Component object model & FCS & Fieldbus control system \\
\hline \multirow[t]{2}{*}{ CORBA } & Common Object Request Broker & FOCS & Flat organizational control system \\
\hline & Architecture & $\mathrm{GC}$ & Gas chromatography \\
\hline \multirow[t]{2}{*}{ COVID-19 } & Coronavirus disease of 2019 & GPC & Generalized predictive controller \\
\hline & & GPS & Global positioning system \\
\hline \multirow{2}{*}{\multicolumn{2}{|c|}{$\begin{array}{l}\triangle \text { Ganti S. Murthy } \\
\text { ganti.murthy@iiti.ac.in }\end{array}$}} & GMO & Genetically modified organisms \\
\hline & & HMI & Human machine interface \\
\hline & & HSCS & Hierarchical structure control system \\
\hline $\begin{array}{l}\text { Departme } \\
\text { Indian Ins }\end{array}$ & $\begin{array}{l}\text { t of Biosciences and Biomedical Engineering, } \\
\text { itute of Technology Indore, Indore 453552, India }\end{array}$ & I & Integral \\
\hline
\end{tabular}




\begin{tabular}{|c|c|c|c|}
\hline $\mathrm{I} / \mathrm{O}$ & Input and output & $\mathrm{SCM}$ & Single-cell model \\
\hline ISA & International Society of Automation & SSF & Solid-state fermentation \\
\hline IoT & Internet of things & $\mathrm{SSCH}$ & System, structures, component, and human \\
\hline IIoT & Industrial Internet of things & TBR & Trickle bed bioreactor \\
\hline IPQC & In-process quality control & USP & United States Pharmacopeia \\
\hline IT & Industrial technology & VOC & Volatile organic compounds \\
\hline ISO & $\begin{array}{l}\text { International Organization for } \\
\text { Standardization }\end{array}$ & WCM & Whole-cell model \\
\hline ISE & Ion selective electrode & & \\
\hline ISFET & Ion-sensitive field effect transistor & \multirow{2}{*}{\multicolumn{2}{|c|}{ Introduction }} \\
\hline IR & Infrared & & \\
\hline KBCS & Knowledge-based control system & \multirow{10}{*}{\multicolumn{2}{|c|}{$\begin{array}{l}\text { Understanding, constructing, and integrating biological } \\
\text { workflows which are mostly systemic in nature can all be } \\
\text { aided by bioprocess systems engineering [1]. The new age } \\
\text { consumers' demand for products is mostly based on envi- } \\
\text { ronmental sustainability in addition to high quality and cost } \\
\text { competitiveness. This necessitates a rethinking and repur- } \\
\text { posing of resources in the domain of bioprocess develop- } \\
\text { ment for effective utilization of natural resources and intro- } \\
\text { duction of new technologies and strategies for meeting the } \\
\text { goals of technical feasibility, resource sustainability, and } \\
\text { economic viability [2]. }\end{array}$}} \\
\hline KPA & Key process attribute & & \\
\hline LCA & Life cycle assessment & & \\
\hline ML & Machine learning & & \\
\hline MBR & Miniature bioreactor & & \\
\hline MES & Manufacturing execution system & & \\
\hline MOM & Manufacturing operation management & & \\
\hline MMI & Man-machine interface & & \\
\hline MCA & Metabolic control analysis & & \\
\hline MOSFET & $\begin{array}{l}\text { Metal oxide semiconductor field effect } \\
\text { transistor }\end{array}$ & & \\
\hline MVDA & Multivariate data analysis & \multicolumn{2}{|c|}{ In bioprocess development, many advances such as strain } \\
\hline MPC & Model predictive controller & \multicolumn{2}{|c|}{ phenotype improvement by bioengineering, process optimi- } \\
\hline MS & Mass spectrometry & \multicolumn{2}{|c|}{ zation, scale-up, optimization-based correlation data, and } \\
\hline NCS & Network control system & \multicolumn{2}{|c|}{ OMICS techniques have resulted in optimized operating } \\
\hline $\mathrm{nCPP}$ & Not critical process parameter & \multicolumn{2}{|c|}{ conditions based on the requirements at the cellular level } \\
\hline nKPP & Not key process parameter & \multicolumn{2}{|c|}{ transitioning to a bioreactor and whole bioprocess sys- } \\
\hline OEE & Overall equipment effectiveness & \multicolumn{2}{|c|}{ tems. Availability of genetic engineering tools, metabolic } \\
\hline OUR & Oxygen uptake rate & \multicolumn{2}{|c|}{ engineering, and OMICS technologies have enabled rapid } \\
\hline OTR & Oxygen transfer rate & \multicolumn{2}{|c|}{ modification and analysis of new strains and in turn, affect } \\
\hline OEM & Original equipment manufacturer & \multicolumn{2}{|c|}{ the time scales for scale-up and commercialization of the } \\
\hline OPEX & Operating expense or expenditure & \multicolumn{2}{|c|}{ bioprocess [3]. } \\
\hline $\mathrm{P}$ & Proportional & \multicolumn{2}{|c|}{ The move to greater efficiencies and economic optimiza- } \\
\hline PI & Proportional integral & \multicolumn{2}{|c|}{ tion of the facilities especially through contract manufactur- } \\
\hline PID & Proportional integral derivative & \multicolumn{2}{|c|}{ ing has moved the bioprocess development toward flexible } \\
\hline PLC & Programmable logic controller & \multicolumn{2}{|c|}{ manufacturing processes that can produce multiple products } \\
\hline PAT & Process analytical technology & \multicolumn{2}{|c|}{ in a single facility. The reduction in cost per unit of a certain } \\
\hline PFD & Process flow diagram & \multicolumn{2}{|c|}{ product due to increased production can also be realized } \\
\hline $\mathrm{P}$ and ID & Piping and instrumentation diagram & \multicolumn{2}{|c|}{ through automation of the processes and development of } \\
\hline PBM & Population-based model & \multicolumn{2}{|c|}{ efficient control algorithms for large-scale production. Tra- } \\
\hline PDMS & Polydimethylsiloxane & \multicolumn{2}{|c|}{ ditional control strategies relied on optimizing control strate- } \\
\hline PSAA & Preventive safety assurance activity & \multicolumn{2}{|c|}{ gies for a fixed number of unit operations in a fixed facility } \\
\hline $\mathrm{pCPP}$ & Potentially critical process parameter & \multicolumn{2}{|c|}{ with little modification is generally the underlying physical } \\
\hline pKPP & Potentially key process parameter & setup. V & the increasing need for flexible facilities, the \\
\hline QbD & Quality by design & need for & dly reprogrammable and reconfigurable process \\
\hline RFID & Radio frequency identification & control & ms becomes a key requirement for commercial \\
\hline RTD & Resistance temperature detector & success & \\
\hline
\end{tabular}

RIF Risk increase factor

RSM Response surface method

RPM Revolutions per minute

SCADA Supervisory Control and Data Acquisition

SUB Single-use bioreactor
Understanding, constructing, and integrating biological workflows which are mostly systemic in nature can all be aided by bioprocess systems engineering [1]. The new age consumers' demand for products is mostly based on environmental sustainability in addition to high quality and cost competitiveness. This necessitates a rethinking and repurment for effective utilization of natural resources and introduction of new technologies and strategies for meeting the oals of technical feasibility, resource sustainability, and phenotype improvement by bioengineering, process optimization, scale-up, optimization-based correlation data, and conditions based on the requirements at the cellular level ansitioning to a bioreactor and whole bioprocess sysengineering, and OMICS technologies have enabled rapid modification and analysis of new strains and in turn, affect the time scales for scale-up and commercialization of the cess [3]

The move to greater efficiencies and economic optimizaon of the facilities especially through contract manufacturing has moved the bioprocess development toward flexible manufacturing processes that can produce multiple products in a single facility. The reduction in cost per unit of a certain product due to increased production can also be realized hrough automation of the processes and development of efficient control algorithms for large-scale production. Traditional control strategies relied on optimizing control strategies for a fixed number of unit operations in a fixed facility with little modification is generally the underlying physical setup. With the increasing need for flexible facilities, the need for rapidly reprogrammable and reconfigurable process success [4].

\section{The objective of this study}

While there are many excellent literature reviews on bioprocesses [5] and process control [6,7], this review will 
specifically focus on the recent bioprocess developments and process control in the context of flexible and rapidly scalable manufacturing process trends. This study will provide an in-depth discussion and synthesis of the historical context, present scenario, future needs, and the challenges pertaining to a variety of bioprocess control systems with a particular focus on the biopharmaceutical industry. This review will address the research gap in the context of the latest trends in control systems and automation of bioreactors in the bioprocessing industry. The whole paper is divided into ten sections. The first section is the introduction, followed by the objective of the study. Section 2 gives an overview of bioreactors and control strategies for bioprocess control. Section 3 discusses the sensing technologies used to date for bioprocess control. State and parameter estimation is discussed in Sect. 4. Sections 5 and 6 discuss process control strategy for various bioreactor configurations and challenges faced with control architectures. Scale-up, risk assessment, economics and environmental safety, historical timeline, and market analysis are discussed in Sects. 7, 8, 9, and 10, respectively.

\section{Brief overview of bioreactor control systems}

Maintaining optimal process conditions for achieving target yields and titers regardless of the bioreactor configuration, nature of the biocatalysts used, and the process disturbances are the essential function of any bioprocess control system. Many researchers have looked into bioreactor control in the past. Disturbances that cause the system to deflect from its optimal state are typically controlled by adjusting the rate of nutrient intake, temperature, pressure, agitation, $\mathrm{pH}, \mathrm{DO}$ concentration, and other critical control parameters [8]. Developing integrative and smart control systems does not necessarily mean developing a foolproof bioprocess for all eventualities, but is more focused on making the process more robust and efficient. Even small and minute improvements in efficiencies and robustness can result in dramatic improvements in the economic viability of the product.

The optimal choice of process control and the control strategies are critically dependent on the type of bioreactors. Shaken devices, stirred-tank reactors, and bubble column reactors with slight modifications to suit process requirements are some platforms of bioreactor that are currently in use in the industrial sector [9]. With the advances in biomanufacturing processes, and the introduction of new types of bioreactor configurations such as single-use and mini/micro bioreactors, the need for sophisticated control systems that are more robust and optimize the processes under increasingly complex operating conditions has increased.

The design aspect of bioreactors in turn is greatly dependent on many factors, one of which includes the type of biocatalyst being used. An example of such can be explained in terms of animal cell culture growth, wherein mechanical brittleness and poor growth characteristics of these cells prompt the high-density cell culture technique, which requires maintenance of the cells inside the bioreactors to be aided by a continuous flow of media. In the field of regenerative medicine, innovations for cell and tissue therapies have emerged in recent decades. As a result, the bioreactor utilized in these cultures should be operated under rigorous control to create goods of sufficient quality fulfilling specific clinical needs, as the products of interest are the cells and tissues themselves which are delicate in nature [10,11].

Product quality regulations, minimal footprint and process flexibility to switch to multiple products on the same production lines are some of the new age requirements for the production of high-value products like biopharmaceuticals and nutraceuticals. For meeting these quality and flexibility requirements in a bioprocessing unit, single-use bioreactors are rapidly emerging as the reactors of choice in upstream bioprocessing. It provides to a certain extent clear economic and time-to-market advantages in conjunction with enhanced performance. Inlet/outlet ports for gaseous exchange, types of filters, valves for pressure control or flow control, and additional ports for sensors are included in these bioreactors, which range in size from 50 to $2000 \mathrm{~L}$ [12]. Other bioreactors such as airlift bioreactors and fixedbed bioreactors are also used in bioprocessing as well as the biopharmaceutical industry. These industry trends have catalyzed new advances in sensor development to new control algorithms.

\section{Control strategies for bioprocesses}

Biotechnological processes (bioprocesses) produce a wide range of goods, including food products such as additives, medicines like monoclonal antibodies, antibiotics, and therapeutic proteins, and also sustainable and renewable products such as biofuels and biodiesel from various wastes [13]. The burden of quality criteria maintenance on bio-manufactured products with almost negligible effect on performance and productivity in the face of increasing industrial competitiveness has resulted in a massive change in the way processes are controlled on a plant scale today [14]. In essence, even though bioprocesses are subject to much variability and unpredictability, precise controllers may be used to direct the process along the intended path and maintain the operations within the desired ranges. While bioprocess model reduction is predictive and helps in the control, validation of bioprocess models (structured or unstructured) is still difficult due to the evolution of the bioprocess dynamics due to process parameter changes or metabolic changes or mutations giving rise to increasing deviation of the models from the predictions [15]. To address these challenges, process 
control can be conceptualized to function at various levels, namely: at the device/activator level, at the process level, and at the plant level. Various control processes, algorithms, and strategies are employed based on the process control needs (a detailed introductory discussion of the various control strategies is provided in supplementary data 2) must be tailored to specific needs of the bioprocesses considering the bioreactor design and operational considerations.

\section{Device/activator level control: classic control strategies}

The actuator level controls represent the most basic level for the control and are ubiquitous in most machines. The actuator level control involves the realistic actuation of the various control devices such as pumps, valves, heaters, electric voltages, and stirrer speeds. In industrial plants, PID controller constitutes the majority of the process control elements for regulatory level process control. PID is regarded as the classical controller which proved to be hugely successful in the industries of electrical, aerospace, and mechanical applications and is very effective for single-input single-output linear systems. The PID controllers have a rich history of development and industrial use and have evolved into commoditized off-the-shelf components that can be tailored for specific applications [16].

With the advent of digital advancements, engineers have integrated digital control concepts with PID. Adaptation, gain scheduling, and self-tuning concepts have been easily integrated with PID control schemes leading to excellent control architectures for processes. While PID controllers are used at the equipment level for control of a single variable such as the temperature or $\mathrm{pH}$ of the bioreactor, they are inadequate for the control of a complex bioprocess due to highly nonlinear dynamics. In such situations, the feedforward process controls can provide greater flexibility for optimal process control than purely feedback control systems such as PID controllers [17].

\section{Distributed control strategies}

Distributed control strategies (DCSs) were introduced as strictly microprocessor-based control developed in the 1970s. This type of system enables the incorporation of advanced process control strategies and builds on the PID controllers. In a DCS framework, host computers are used to perform Level 2 type tasks (based on ISA 95 Purdue Model) which are basically optimization algorithms and advanced control strategies, while the actual controls at the device level are performed by the PID controllers. Since the communication between the PID controllers and the master controller is critical for error-free functioning of the control systems, various data transmission links, protocols with error correction, and redundancies were developed. With the implementation of DCS, the operators could supervise and control the entire plant from centralized control stations that provided printers for alarm logging, report printing, or hardcopy of process graphics and video consoles for real-time viewing of the processes. Regulatory level control functions, such as PID algorithms, are implemented by remote control units, which can also include data gathering and extraction capabilities. As a result, data storage devices were used to store process data for control and process analytics. Software, not hardwiring, was used to communicate and interact with controllers, inputs, and outputs. As a result, DCSs have transformed many elements of process management, from the look of the control room to the widespread usage of advanced control methodologies [18].

The working competencies of DCSs have increased manifold since the early 1980s. Within process control, there has been a steady growth in the usage of a digital framework for communication technologies. DCS framework also allows for some advanced control strategies to be implemented. As communication methods become more digital, most of the local control units perform their analog-to-digital (A/D) and digital-to-analog (D/A) conversion and are housed in equipment rooms closer to the process. A bidirectional flow of information is established back to the control room using digital communications over a coaxial or fiber-optic connection, saving money on wiring. Smart transmitters and actuators are becoming more common with the increasing use of digital communications technology. These devices, having their own microprocessor, perform activities such as autocalibration, autoranging, signal conditioning, characterization, and self-diagnosis on site. As a result, the operations performed by the local control unit or the data collection unit are decreased [19]. The features that have made DCSs popular are:

- The usage of data highways and remotely located local control units reduce wiring and installation costs.

- The reduced panel area needs space in the control room.

- Customized screens with improved operator interface.

- Due to the modularity of the DCSs, expansion is much easier.

- Increased control architecture flexibility, allowing controls to be updated without rewiring.

- Reliability and redundancy are improved.

Client-server (personal computer) configuration Previously, control systems consisted of a single manufacturer who provided the entire plant automation system due to the lack of interoperability with other vendor products. The current advances propagating transition of systems to "plug and play" came into the picture with the help of software technologies such as CORBA and COM along with programming languages such as Java/Python and the internet/ 
intranets. Personal computers are increasingly replacing panel boards as operator stations, making it easier to communicate data from the control system with other programs operating on personal computers or over the network [20]. The concept of the component object model has been introduced along with DCSs to generate more open solutions for process and data-oriented problems. These technologies enable the integration of the best applications from various vendors to improve plant-wide control.

\section{Programmable logic controllers based strategies}

PLCs are microprocessor-based devices that execute simple binary logic for sequencing and interlocks since their launch and have been ruggedized and adapted for control manufacturing processes. They were designed to be used with hardwired electromechanical and electrical relays, switches, pushbuttons, and timers in the first place. Simplicity (in terms of calculations), ease of adjustments, and alterations enabled its adoption in process industries to evaluate and implement PID algorithms, thus replacing the need for hardware-specific PID controllers. The PLCs can handle sequential logic and are equipped with an intrinsic ability to time for programmable delays, alarm and timer-based triggers, and extensive capability for handling multiple inputs and outputs. Current industrial practice is to use PLCs and DCSs in an integrated fashion with separate provisions for operator I/O [21].

\section{Plant level control strategies}

With increasing digitization and networking of the processes, plant-wide process control software has been developed. The application software is hosted on dedicated servers that provide integrated solutions and management of plant-based projects starting from PFD, P \& ID, electrical instrumentation, and control engineering solutions, thus providing an integrated view of the complete plant to the control engineer. This is essential for keeping the CQAs of the final product close to specification in the face of severe and persistent disturbances. The software also provides capabilities for simulating the impact of selected disturbances along with the effectiveness of control strategies and final products to maintain the CQAs at the desired values, especially during the transition of processes from batch to batch or switching of the processes. Several commercial application software, such as COMOS (Siemens), are commercially available that provide extended features such as 3D virtual reality models in addition to the capabilities described above [22].

Efficient engineering strategies are easily implemented through in-built software packages wherein the process can be customized according to user needs along with technical solutions to the process, which also is provided from the server while building the process. Process parameters datasheet gets continuously updated automatically if the user or the process engineer makes changes even at the last moment just before process startup. Thus, these kinds of plant-wide control servers or interfaces provide for a unique range of solutions in the biomanufacturing domain [23].

\section{Supervisory Control and Data Acquisition control strategy}

Supervisory Control and Data Acquisition (SCADA) systems are similar to microprocessor-based PLC and DCS systems for plant-wide control. SCADA systems are adopted in industries that require flexible and scalable control system architecture with multiple process redundancies. Supervisory control addresses the following domains:

- Computation of set point causing an impact on energy, quality, and production volume.

- Startup/shut down/ emergency operations.

- Control reconfiguration/tuning.

- Performance monitoring/diagnostics.

- Operation interface.

SCADA is similar to PLCs and DCSs in terms of built-in features like microprocessors-based control. SCADA systems are software applications installed on standard computers or servers that allow data to be transferred between various input and output devices as well as other computerbased process data systems [23,24].

\section{Development of bioreactor control system}

The starting point to any control structure design procedure is to set the desired functionality of the process which is the plant operating goal. A conceptual control design study is based on the following characteristics [25]:

- Functionality.

- Top-down analysis.

- Bottom-up design.

- Evaluation of the control structure performance.

Simulation of various process controls is also critical for the development of a bioreactor control system before going in for the final implementation of the process model. To reduce the hardware dependency and fine-tuning of the process model, it is very much necessary to have software for testing and verification which can be developed as a.NET application. The software is built such that it will simulate the behavior of cell culture and must be able to send process values and receive set point and control values from PLC. The cell culture can be based on ordinary differential equations describing cell density, dissolved oxygen tension, 
substrate concentration, and many such parameters. The software simulator also must have a graphical user interface (GUI) where process parameters can be specified and simulation behavior modified as per changes required during execution. Such operations will enable better process development, minimize problems, and also give us a fair idea of trade-offs associated with various parameters when used in real for product development [26].

\section{Trade-offs in controller design}

A real-world controller design is an exercise in balancing the considerations for a speed of response, robustness, disturbance rejection, and cost of the control strategy [27, 28]. A trade-off can happen at any level of industrial automation levels or at regulatory control levels depending on the importance of the product being developed in the plant. It is the foresight in certain cases and intensive modeling approaches combined with data analytics that gives the process engineers the defined weightage of parameters that can be given high or low priority. Many times during process development, tweaks and changes in model structures are required to validate the model for further use in the development of the process. Therefore, a thorough understanding of the various types of bioprocess models is crucial for developing sound process models.

\section{Identification and development of model structures}

Modeling gives a basic idea about the process, especially in the case of nonlinear processes, wherein modeling parameters may or may not work for the process either due to poor availability of process variables to formulate the necessary equations or if it is in case of an industry level there is a possibility of plant-model mismatch [15]. The applicable process knowledge, on the other hand, is substantially less than that required to create a mechanistic model based on mass balances. The amount of data, on the other hand, is far greater than what would be required to identify a mechanistic model. It should be noted that less empirical data may be adequate to identify an accurate model, demonstrating that more data are not always necessarily required for a process to function at its optimal efficiency [25].

A complete flowchart showing all the model architectures has been described with utmost clarity as obtained from [ $[15$, 29]. Both the references have shown model structure classification on a generalized and much more distinct classification has been demonstrated wherein one type of classification is based on bioprocess growth modeling and another on nonlinear (mathematical) model classification. However, in this figure, an attempt has been made to summarize all the model classifications under one umbrella called bioprocess modeling as shown in Fig. 1.

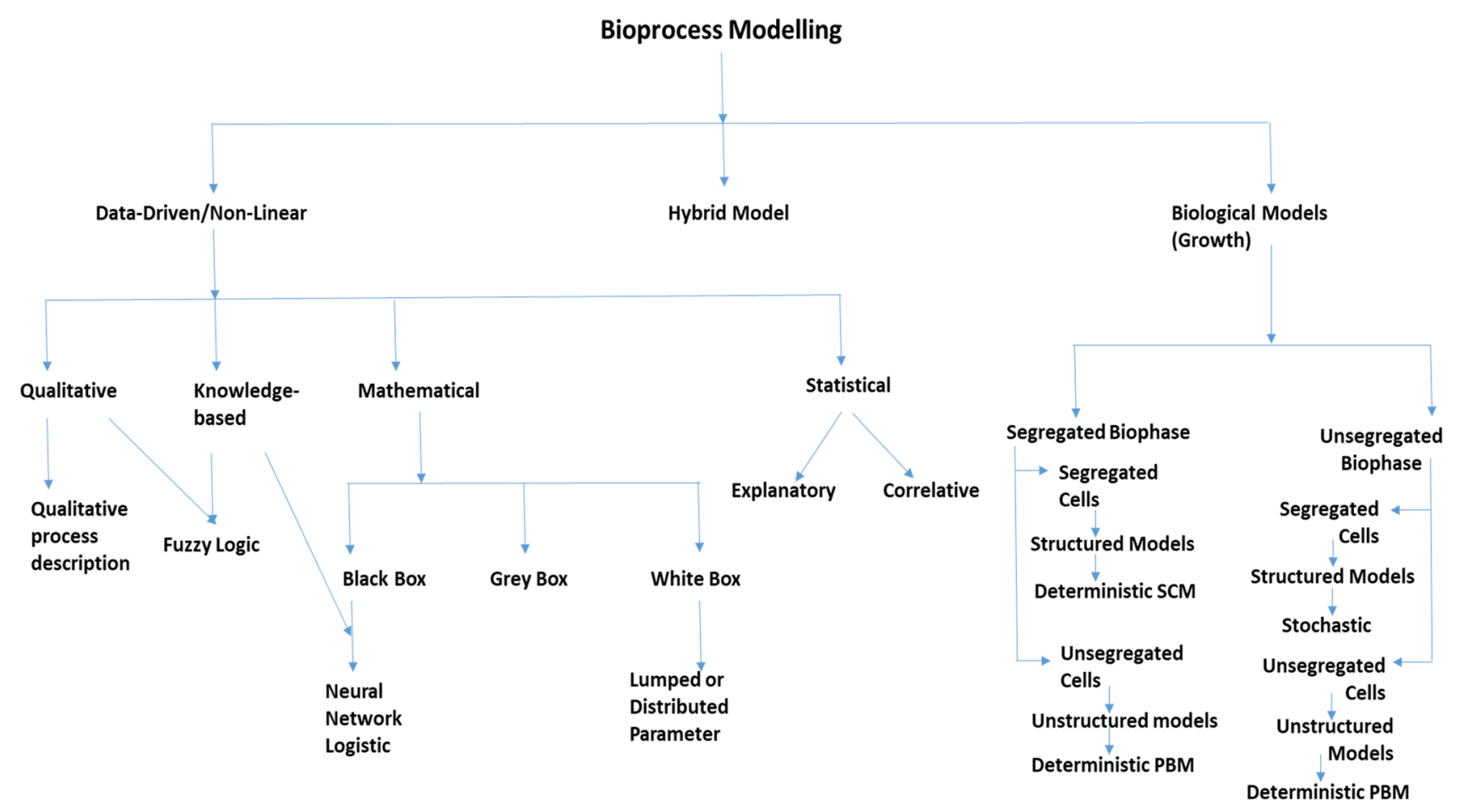

Fig. 1 A detailed classification showing all the different types of bioprocess modeling 
Unstructured models, which are widely used, fail to account for changes in biomass composition as a result of environmental changes. Being simple to code and easy to simulate with software such as LabVIEW, controllers which are model-based can quickly be constructed utilizing unstructured modes and can be implemented online into the software giving the operators an interface for communication with bioreactor platform [30]. These types of models are widely known for providing accurate representation only when growth conditions are balanced. As a result, controllers built with these models may work poorly under specific metabolic situations that are not properly represented by them, thereby being disadvantageous due to a lack of intrinsic metabolic information. However, structured models can give better information regarding dynamic metabolic conditions and microbial biomass composition. Models are further classified based on the level of detail with which they represent different phenotypes and the characterization of internal components or cell "structure" [31].

Unsegregated models treat microbial cultures as homogeneous or population based, while segregated models treat cells as distinct entities or single cells and allow them to be classified into interest groups. Extrapolation competencies of structured and segregated models are superior to those of unstructured models. Therefore, controllers created with these models describe the predictable response of the system to perturbations. The drawback of adding additional cellular data is that parameter estimation and assimilation of this function into the controller becomes difficult, if not impossible. As a result, one must choose between the simplicity of application and the minimum complexity required to solve the specific circumstances pertaining to the problem under consideration.

\section{Online sensor development and measurement}

With regard to changing process dynamics, a need has been observed in real-time monitoring for processes wherein the measured parameters are processed instantaneously as and when the process is ongoing. Even though sensors technology has improved quite a lot with the coming of smart sensors and actuators [27], the need for off-line analysis has not been fully eradicated. Even in well-established companies running continuous or perfusion culture batch processes, offline measurements are a necessary part of the process often referred to as in-process quality control (IPQC).

While real-time sensors do have the ability to process and analyze the information in real time, there is a danger of unprecedented process deviations/incidents occurring due to faulty sensor data. However, some sensors do have alarms that provide an early warning to the system before any mishap to the process starts to occur. With regard to industries while conducting CMO/CDMO-based processes, often it happens that for a particular process the company which conducts the manufacturing process often dominates the system of the third party company just to ensure that there is no possibility of process variability. For example, turning the alarm systems off for certain sensors like Hamilton $\mathrm{pH}$ probes or for flow meter sensors to ensure smooth loading of the eluted product takes place without any unnecessary interruption is pre-determined before the process runs in some cases.

Along with single-use bioreactors, single-use sensors have been developed by several companies like Finesse [12]. They have built a series of optical sensors (TruFluorTM) that use a wholly disposable element (pre-programmed RFID tag) that arrives inserted and sterilized from the time of manufacture with the single-use container, ensuring that the sterile barrier is not breached. All the disposable elements are ensured as gamma radiation resistant, and all wetted materials have either been tested to USP Class VI standards or have been designated a priori as ISO 10993 compliant. Additionally, they can be pre-calibrated and can be set up to enable electronic data traceability.

\section{System identification}

System identification can be defined as a procedure that involves perturbation caused by an input variable and then retrieving the system's output variable data, thereby determining the model. Using input-output data, an appropriate method is used to find the unknown parameters in the parametric model. The model is then tested against the experimental data and fitness on the system.

Thorough system identification is essential before the startup of the process or introducing any new changes into the system, the process engineer should be aware of the system configurations and input-output characteristics of the system. A crucial understanding of the system's upper and lower limits to anticipate any problems is essential before the start of operation. To operate the system, one must first determine the relationship among the input and output variables, as well as construct a system model. It is feasible to incorporate input-output data from experimental studies or mass-energy balances when modeling the systems. However, in complex systems, by using mass-energy balances, it is difficult to construct a model, and in some circumstances, these balances may be inconsistent to appropriately define the system. In such circumstances, model creation using system identification methods from experimental input/output data becomes more useful [32].

\section{Optimization strategy}

Optimization criteria are set according to the bioprocess model or the modeling equations that have been developed 
for the process wherein the process models play an important role in terms of the kind of model being proposed which may be structured or unstructured [33]. Identifying optimal operational strategies for metabolic products is difficult. A variety of metabolic products, the complexity of bioprocesses, a number of control variables, and the system's fuzzy nature even if it leads to developing optimal operating techniques do increase total profits, but it is not always or necessarily a favorable choice. This happens because knowledge of understanding metabolic profile and pathways is still not very clear and thus can be favorable in terms of economy in certain cases only but not for all. Several operating modes, such as batch, fed-batch, and chemostat, have been investigated for effective bioreactor operation, and some are widely used in the industry.

Methodologies based on MCA and FBA form the basic framework of some of the optimizations of certain bioreactor systems [34]. MCA is typically used in metabolic pathways that are in a steady state. Control distribution of various fluxes and concentrations can be determined using MCA. This knowledge aids in the manipulation of metabolic fluxes, which is one of the primary objectives in the domain of metabolic engineering. It is mandatory to express any system in the form of a reaction network to apply MCA to it. After the system has been described in this way, MCA can be used to calculate gradient information about the system that is qualitatively equivalent to the flux and concentration control coefficients. The MCA method is an excellent mechanism for investigating system behavior in terms of control and response coefficients. The information about the system interactions is implicitly contained in these coefficients. In fact, the system behavior may be simply examined on an integrated basis with subprocesses and all parametric determinations.

Metabolic pathways and their various research involving tweaking of certain enzymes and substrates give the desired output which involves metabolite overproduction, network rigidity, flux balance analysis, metabolic flux analysis, and many more [35]. Researchers have solely concentrated on enzyme amplification or changes of several intermediary enzymes along the product pathway to increase metabolite overproduction. Overproduction of many metabolites, on the other hand, necessitates significant redirection of flux distribution redirection in primary metabolism, which may not be easy to achieve after product deregulation because metabolic pathways have evolved to have control architecture that resist flux changes at branch points. The idea of metabolic stiffness, which includes a method for locating and deleting rigid branch points within an experimental framework, can be used to engineer better strains with greater process flexibility.

\section{Sensing technologies for bioprocess control}

Sensors form an integral part of bioprocess control strategies. With the advances in bioreactor designs and operations, the requirements for sensing technologies have also evolved. For example, the increasing adoption of singleuse bioreactors (SUBs) in the last two decades necessitates new developments in sensing technologies. Many sensors that are currently used in SUBs are those that have been used in traditional stainless steel bioreactors and are not optimal for use in current bioreactor designs [36].

\section{Temperature, pH, DO, and agitator speed}

$p H$ sensors The $\mathrm{pH}$ of the media is a critical variable in the operation of bioreactors. $\mathrm{pH}$-sensing technologies can be broadly divided into the following categories: porous glass electrode-based electrolyte-filled sensors, MOSFETbased ISFET $\mathrm{pH}$ sensors, optical property-based $\mathrm{pH}$ sensors, potentiometric sensors, electrochemical-sensing technologies.

The glass $\mathrm{pH}$ electrode is still used in most $\mathrm{pH}$ sensors, which was created in the 1960s. Because of their excellent repeatability, long life, and precise Nernstian response, glass electrodes have long stood the test of time in industries [37]. Ion-selective electrodes (ISE), such as the electrochemical $\mathrm{pH}$ electrode, are a huge sub-category based on the principle of potentiometry which is a method to measure potential with no current flow in between electrodes. The indicator electrode compares potential variations across the solid-state membrane between the internal solution and the analyte to the reference electrode. In the case of modern $\mathrm{pH}$ meters, a reference electrode is generally incorporated inside the probe body for comparing test $\mathrm{pH}$ value to baseline, resulting in structural bulkiness. The main challenge with the glass electrode-based $\mathrm{pH}$-sensing is that these sensors are fragile, require regular maintenance in terms of replenishing the electrolytes, and have fouling problems when used in complex media typically used in bioreactors.

Electrochemical sensors In these types of sensors, an electrode is used that converts the analyte into a measurable substance. For example, in the case of gas sensors, the concentration of the target gas is measured by either oxidizing or reducing the target gas at the electrode and the resultant current used for conversion is measured. Typically, for any electrochemical sensor, it consists of three electrodes-working, reference, and counter electrode. The working electrode is the one where a redox reaction takes place with the flow of ions. For each reaction in the working electrode, it draws a response from the counter 
electrode. Owing to the system's working, the counter electrode will try to balance the change in the potential by balancing the reaction between the detected gas and the working electrode. This balancing gas is dynamically monitored by the main reading of the sensor. Along with these electrodes, a gas-permeable membrane is present which separates the aqueous component from the gases and also regulates the amount of gas reaching the working electrode, thus preventing leakage inside the sensor [38].

ISFET-sensing technology It is based on a field-effect transistor which is ion sensitive in nature used for measuring ion concentrations in solutions. An attachment of ions or molecules to an ion or analyte sensitive layer that is coated to the gate membrane of the transistor is the measurement technique in ISFETs. Source and ground electrodes are grounded to a substrate and connected in the circuit. The attachment of the analytes/ions to the gate membrane causes a change in the electric potential between source and ground electrodes and this change is the measure of the concentration of ions/analytes. ISFET can be regarded as the first biosensor-field-effect transistor to be used in biological solutions and hence also known as BioFET [39].

Sensors devices like optical $\mathrm{pH}$ sensors with the functionality of non-contact sensing and lower size are also gaining popularity. They work by measuring the absorption or fluorescence of a $\mathrm{pH}$ indicator dye. Absorption dyes, such as phenol red, bromocresol green, and phenolphthalein, and fluorescent dyes, such as 8-hydroxy-1,3,6-pyrenetrisulfonic acid trisodium salt and fluorescein, are examples of the dyes utilized. So they are classified as absorbance and fluorescence-based technologies depending on the measurement technique used for the detection [39].

In comparison to electrochemical sensors which detect the concentration of the $\mathrm{pH}$ indicator, optical sensors measure only the activity of $\mathrm{H} 3 \mathrm{O}+$ ions. An optical sensor has several advantages over an electrochemical sensor: it is least invasive, delivers continual measurements, and does not require a separate reference electrode, proving that miniaturization is relatively easy. This enables the usage of patching systems. Photobleaching is one of the most significant issues with these types of sensors. The breakage of covalent or non-covalent bonds generated by non-specific binding triggered by excitation light causes photobleaching of the indicator dye, whether it be a fluorophore or a colorimetric dye, rendering it unable to glow. Over time, this leads to inaccuracy. The primary trends in optical sensor development point to a shift toward miniaturization, which will reduce costs and increase mass producibility while requiring new manufacturing methods. The optical $\mathrm{pH}$ patch is one such device, which combines a $\mathrm{pH}$ sensor onto an adhesive disc that is attached to the bioreactor surface. Another area of research that will help in the usage of disposable bioreactors is the development of single-use optical sensors, which will prove to work well with disposable bioreactors [40].

Certain bioprocesses, like anaerobic processes, are still very much highly dependent on 'manual laboratory analysis' and the adaptation of such system by a 'qualified operator' wherein spectrometric, titrimetric, and some other principles have been explored as sensing options for anaerobic digestion [40, 41]. The processes being studied and the magnitudes of the energy changes involved require different spectroscopic techniques to work over various, limited wavelength ranges within the electromagnetic spectrum [42]. Spectroscopic bioprocess monitoring generates a vast number of spectra, each with a significantly lower information content than the data volume, from which useful information should be extracted quickly.

Fluorescence spectroscopy including 2-D fluorescence spectroscopy emerged in the early twenty-first century as one of the pioneering instruments based on optical-sensing elements [40, 41]. The fluorescence measurement of the reduced form of nicotinamide adenine dinucleotide (phosphate) $[\mathrm{NAD}(\mathrm{P}) \mathrm{H}]$, which was initially utilized for in vivo measurements by Duysenz and Amesz [43], is the most popular fluorescence sensor.

Temperature The control of temperature in a bioreactor is a well-established technology and a precision of $0.5^{\circ} \mathrm{C}$ or better is routinely achieved. Typical temperature sensors in industrial settings are thermocouples, resistance temperature detectors (RTD), and thermistors. The choice of a particular temperature measuring instrument is dependent on the stability, sensitivity, accuracy, linearity, and sterilizability of the sensors. The J- and K-type thermocouples are commonly used for temperature-sensing applications in bioreactors. The most common RTD is made of coil-type platinum resistance wire Pt100 type sensors. The most common type of thermistors is used in specialized applications where the required sensitivity is much higher, but can operate only in a limited range of temperatures ( -50 to $\left.200{ }^{\circ} \mathrm{C}\right)$. The temperature control in an animal cell bioreactor is generally less complicated than in a microbial fermenter due to lower metabolic activity which results in a lower amount of heat to be removed from the reactors [44].

Clark-type DO sensor Developed by the principle of microfabrication, it consistsof three electrodes on a glass substrate, an FEP oxygen-permeable membrane, and a PDMS reservoir for storing few cells in solution. [45]. This electrode established itself as the first glucose biosensor in 1962.

Impeller speed Standard single-impeller or single-baffle stirred tanks are frequently criticized for uneven shear characteristics and energy dissipation, both of which are known to be hazardous, particularly to microorganisms in bioreactors. In the case of multiple-impeller systems, 
impeller speeds will be reduced for equivalent power dissipation, resulting in lower values of the maximum shear generated. It should be noted that in single- and multipleimpeller systems, the shear forces-related contributions from the bubble bursting at the interface will be the same, and thus the overall cell destruction rate due to fluid shear is expected to be lower in multiple-impeller systems dissipating the same overall power. Multiple-impeller systems will thus be preferred where shear sensitivity to microorganisms is an important criterion of design [46].

During the installation of impellers or any such rotating devices, it is often qualified using instruments like a tachometer for sensing whether the desired rpm matches with the reading in the tachometer thus verifying $\mathrm{rpm}$ values to be close to the optimum value or not. CFD modeling and various characteristic mixing predictions are required to achieve the desired impeller speed and control. RPM shifts are crucial for maintaining cultures in the upstream unit for product maximization, thus implementing such shifts is crucial to the process and its control architectures associated with it.

\section{Other variables such as headspace gas analysis}

Although headspace gas analysis does play an important role, it is only needed wherein the gas component evolving is a product of interest to us: for example, VOCs' component analysis or $\mathrm{CO}_{2}$ analysis. Headspace gas analysis can be categorized under non-invasive sensing technology as it allows the measurement to be performed without breaking the boundary between the bioprocess stream and the surrounding environment [47]. Integration of techniques such as gas chromatography with headspace sampling results in faster analysis, thus reducing the possibility of sample contamination. Another method called direct injection mass spectrometry (DI-MS) is also used wherein gaseous analytes from headspace are directly introduced in the MS system, simply reducing sample analysis procedures. The optical array sensing approach has also demonstrated outstanding results in the detection and identification of a variety of analytes, including hazardous compounds, and hence can be used to detect and identify VOCs that collect in bioreactor headspaces. The off-gas analysis is used to design colorimetric sensor arrays coupled to optoelectronic readers for the detection of various bacteria and fungi.

Inline GCs are commonly used for headspace gas analysis. Specific gas sensors, IR sensors for $\mathrm{CO}_{2}$, and humidity sensors are used where relevant. $\mathrm{CO}_{2}$ sensors in particular along with D sensors can be used to calculate the OUR which is a very critical parameter for microbial growth.

\section{Biosensors}

Researchers working in interdisciplinary fields such as biotechnology generally agree that biosensors are made up of two parts: a biological molecule or cell that detects the analyte and a transducer that turns the detection event into an electrical signal. The ability to recognize molecules of a given analyte is a significant biological trait for which biosensors are exploited. The possible biological components fall into two broad categories:

a. Biocatalysts (enzymes, microbial, plant and animal cells, and subcellular organelles).

b. Bioreceptors (antibodies, lectins, cell membrane receptors, and other specific binding agents) [48].

Biosensors were built keeping in mind the influence of enzyme sensitization kinetics and also enzyme-sensitized detectors. There are enzyme-sensitized amperometric biosensors, potentiometers, thermistors, semiconductor devices, and immobilized cell-sensitized sensors.

From the transducer's point of view, biosensors can be classified as electrochemical, optical, thermal, and piezoelectric devices. In biosensors, electrochemical detectors are the most widely used transducers. Many enzymes consume and/or create electrically active species that can be measured using amperometric, potentiometric, or conductimetric methods.

Even though several optical transducers in biosensors have been fabricated, their application is mostly restricted to illumination or light emission [48]. But P.O'Mara et. al. had proposed that biosensors exclusively drive the technology for better sensor development for bioreactors in the twenty-first century with the help of electrochemical sensors through the process of miniaturization [49].

\section{State and parameter estimation}

The purpose of state estimation is to deliver reliable, realtime state variables defining a process using available quantitative/qualitative knowledge of the process in conjunction with the known process measurements. The state estimation is critical where some of the process variables cannot be measured in real time to estimate the process states. The methods that provide an online estimation of unmeasured process variables and parameters are called state estimators.

Fundamentally, the unmeasured states can be estimated if the measured outputs/states contain sufficient information about the process dynamics to infer the unmeasured state. The observability criteria can be used to mathematically test for the sufficiency of the measured outputs to measure/estimate all the states. For a fully observable system, 
the estimates of the unmeasured states can be done using observers. Observers are sometimes known as soft sensors since they are designed to be asymptotically convergent to prevent measurement mistakes from proliferating [50]. Model mismatches and process uncertainties can be compensated significantly by an online estimate of unknown bioprocess variables and their input into the control regulation. This estimated state variable information can be used to supplement traditional sensor data and delayed measurement information, allowing controllers to get frequent feedback signals and improve control performance. The estimatorsupported control schemes can lead to improved process operations with enhanced productivity. As a consequence, bioprocess state estimates must be integrated with process systems engineering techniques including improved process control, fault detection, and diagnosis [51, 52].

An example of a parameter estimation technique can be the multi-response technique which can be used to estimate the course of simulations from the nonlinear model. Identifying nominal process parameters from literature, which is generally based on laboratory level studies, leads to differences in experimental data, whereas appropriately calculated process parameters result in a greater agreement. This type of change can be linked to the hydrodynamics of large-scale reactors, which exhibit substantially more complex behavior $[32,49]$.

\section{Process control strategies for various bioreactor configurations}

Control schemes for bioreactors are based on the process requirement. In some cases, different control schemes can be applied to a particular bioreactor or in a certain application, a single control or maybe a hybrid control scheme can prove to be effective against a wide range of bioreactors.

\section{Batch culture}

Batch bioreactors are one of the most common types of bioreactor configurations used in the pharmaceutical industry. The distinguishing feature of the batch reactor is that once the reaction is initiated, the substrate is not supplied during the batch operation. This means that the process conditions continuously change during the batch reaction process and surprisingly require more sophisticated control algorithms for maintaining near-optimal process conditions. There are inevitably small changes in the initial conditions of every batch which poses challenges to the reproducibility in terms of the process yields and titers if the initial quality control and the process control are not maintained within fine tolerances [53]. Although it has some important applications $[21,54]$ as a kinetic model study in processes like lactic acid fermentation and adaptive se tpoint control system for microbial cultivation processes, most of the processes are oriented toward fed-batch and continuous systems.

\section{Fed-batch culture}

The importance of fed-batch operations in a plant is that the reactors involved in this type of process can maintain an optimum level of substrate concentration throughout the course of the bioprocess by controlling the feed properly [55]. However, the product concentrations continue to accumulate posing challenges if the biocatalyst is prone to product inhibition. In general, a fed-batch operation may be advantageous when the specific rates of growth and/or product development are non-monotonic functions of the substrate concentration, and it is then important to calculate the best substrate feed rate. The usual goal of fed-batch bioreactor optimization is to maximize either biomass or metabolite production, and the optimization has historically been done with regard to substrate feed rate. Singular control presents a challenge in determining the ideal substrate feed rate, because the control variable occurs linearly in both the dynamic equations describing the process and/or the performance index to be optimized [56].

\section{Continuous culture and perfusion culture}

Though researchers are shifting their gear to continuous culture as an easy recovery of product and easier process control, it still has its disadvantages in the form that crossfunctional teams involved in the process along with process operators have to stay in continual alert mode to keep a tab on the ongoing process in a plant facility. Perfusion culture differs from continuous cultures in the fact that in perfusion the cells are not retained in the bioreactor, but are collected in a cell retention device by the process of alternating tangential flow filtration wherein the cells get retained in the filter of the ATF, while the spent media is moved back into the bioreactor unlike continuous culture where the cells stay inside the bioreactor for the whole process [57].

\section{Solid-state bioreactors}

The name of such bioreactor is derived from the bioprocess technique known as solid-state fermentation or otherwise referred to as solid-state fermentation bioreactor, which has proven to be quite successful in recent years and has been looked at as a substitute to the submerged fermentation process. One of the key advantages of this process is to develop therapeutic enzymes, whose yield is low but are of high value and whose production is difficult using conventional processes [58]. The metabolic heat removal is difficult to remove from a bed of particles in which the 
interparticle phase is occupied by air than it is to remove this heat from a continuous aqueous phase. Water activity and the composition of the solid substrate play a crucial role among several key difficulties. The thermal properties of a continuous aqueous phase, such as thermal conductivity and heat capacity of liquid water, are superior to those of a bed of moist solids with interparticle air. Cooling the bioreactor from the outside is the greatest technique to eliminate any heat that will be generated within it, thus avoiding any damage to the contents of the bioreactor, and the revolving speed would allow for quick cooling. The impeller rotation has several purposes: it helps to appropriately expose the substrate-strain combination, resulting in a larger surface area for the reaction to occur, and it also allows heat to drain, resulting in increased productivity. During SSF, the mixing procedure is an issue keeping in mind the sensitivity of the microorganism being used. The sensitivity of the microorganisms can be managed by selecting an optimum rpm that does not disrupt the balance of the substrate strain mixture and is calculated based on characteristics connected with the design of the specific bioreactor, such as the bioreactor's dimensionality for rpm determination [59].

\section{Trickle bed bioreactor}

These bioreactors have been in the market for over 40 years and are used when a reaction involving catalysis by a solid catalyst is carried out at least between two components-one in gas and the other in a liquid phase [60,61]. The advantages of TBR include a flow rate of liquid matches that of plug flow leads to higher reaction conversions. The usage of catalysts is minimal, especially when costs are concerned. There are no moving parts present in the system of TBR. TBRs holds the possibility of operating at higher pressure and temperature. The sizes of the TBRs can vary from small scale to large scale. The reactions taking place in TBRs have a low liquid-solid volume ratio causing less occurrence of homogeneous side reactions. CAPEX and OPEX pertaining to TBRs are also low compared to some other bioreactors. TBRs also have the feature of varying the liquid flow rate set according to catalyst wetting and also heat and mass transfer resistances.

The disadvantages of TBRs include lower catalyst activity efficiency in certain reactions because of the large size of particles. There also exist limitations in terms of the use of viscous and foaming liquids. If side reactions occur inside the reaction volume of TBRs, there is a constant risk of increasing pressure drop or obstruction in the working of catalyst pores can be observed. Catalysts used can also be rendered ineffective if there are low liquid flow rates and the reactor diameter/particle size ratio is less than 15-20. TBRs also have the difficulty of reaction heat which could give useful information on the gaseous component being produced in the reaction. [61]

\section{Microbioreactor}

Microbioreactors can be referred to as microfluidic tools which are capable of providing high-throughput screening of bioprocess materials in a fast and cheap manner using a minimal amount of reagents [62]. They can be used as an array of microfluidic tools in case of process continuous perfusion culture modes are at play [63-65]. Furthermore, as compared to traditional bench-scale reactors, such instruments are more adaptable and may provide for improved parameter controllability. As a result, the scientific community has been paying attention to this technology in recent years.

Microbioreactors emerged as a result of the convergence of two major fields: microfluidics technology and molecular biology. The advent of photolithography led to the concept of microfabrication, allowing scientists to create the first microdevices: micro-sized transistors in the latter half of the century.

As long as developments in instrumentation allowed it, the concept of lab-on-a-chip technology arose. Microbioreactors were constructed and studied to do so, with characteristics such as growth rate, dissolved oxygen (DO), temperature, and $\mathrm{pH}$ levels analyzed.

Microfluidics is a science that analyzes and takes in fluids in small quantities using micrometric channels as a result of the advancement of microtechnology. Microbioreactors are a derived product from the domain of microfluidics, and they are one of the many applications that this technology potentially introduces.

Controlling fluid dynamics and applying it to microsystems can be highly beneficial for studying genetic responses to environmental changes, diagnostics, molecular screening, microbial screening, and cellular microenvironment simulation.

\section{Single-use bioreactor}

Single-use bioreactors provide a versatile and process-oriented design along with a wide range of mixing principles. Stainless steel bioreactors have been studied for more than five decades and many methods for characterization of these bioreactors have evolved including scalability. The study of single-use bioreactors' scalability issues addresses evolving bioprocess industry requirements such as the need for faster batch turnaround times, lower contamination risk, and easier operation and maintenance. SUBs are suitable for the cultivation of shear-sensitive cells, such as mycelium-forming organisms and stem cells. SUB systems are known to be easily integrated with continuous perfusion processes [66]. 
Another type of single-use bioreactor is rocking motion wave bioreactor (RM20/50) which also is a part of the seed train process in perfusion culture and helps in the first scaleup procedure in terms of cell growth and expansion. It usually comes in either $20 \mathrm{~L}$ or $50 \mathrm{~L}$ bags which are adjusted in rocking motion and the temperature and $\mathrm{pH}$ optical probes are inserted, thus keeping the medium under constant shake and maintaining $\mathrm{DO}, \mathrm{pH}$, and temperature for a certain period as determined for the specific process.

\section{Challenges in deploying control strategies}

Due to high process variability, the complexity of biological systems, the need to operate in a sterile environment in most cases, and the relatively few real-time direct measures available to help describe the status of the culture, bioreactor controlling poses unique challenges. This has resulted in some innovative solutions as well as the identification of areas that require additional research and development [67].

\section{Similarity principles for scale-up}

Similarity principles are used for the scale-up of bioprocesses, but face several practical challenges since achieving both geometrical and kinematic similarity is impossible [68]. When the basic physics underlying the process is known and the relevance of various parameters is known, the Pi-theorem can be used to derive the dimensionless groups of numbers and the relationships among them to perform the scale-up process. Since achieving a complete similarity is not feasible, a partial similarity is often the goal of the designers. Bioprocesses also require physiological similarity during the scale-up, making the process of bioprocesses even more challenging than the scale-up for chemical reactors. Physiological similarity refers to the maintenance of conditions that maintain similar substrate feeding rates, product accumulation/removal rates, biomass growth rates, $\mathrm{pH}$ and temperature, and micro and macronutrient concentrations in the bioreactor as in the laboratory scale studies where the process was developed. $[69,70]$.

\section{Mass transfer considerations}

Scale-up with respect to oxygen mass transfer has been a domain of research for certain kinds of bioreactors like U-loop and airlift-loop bioreactors. Oxygen transfer rate and multiple impeller usage for good mixing are some of the techniques used to do mass transfer, and considerations like what values or what should be a certain impeller size were to be taken into consideration $[71,72]$.

\section{Biocatalysts considerations}

Usage of biocatalysts in bioprocess either accelerates or improves the process in numerous ways and, combined with the help from the systems biology domain, have proved themselves for scale-up considerations to a moderate level [73]. Increased agitator speeds can promote mass transport inside a bioreactor; nevertheless, biocatalysts are generally sensitive to shear fields induced by increased agitator speeds, resulting in a decline in productivity. For example, when the Rushton turbine was set to $1000 \mathrm{rpm}$, the specific production rate of a penicillin fermentation (gram per cell dry weight) was approximately $50 \%$ lower in a 6-L CSTR compared to $600 \mathrm{rpm}$, which is a clear indication of the fact that increased turbine speed does not always improve the reaction and may in turn damage productivity due to other factors [74]. Not only the speed, but also sometimes heat transfer plays a huge role in scale-up considerations, as certain processes do get affected due to the heating up of reactors whether or not biocatalysts are used.

\section{Equipment challenges}

Although there is much commercially available equipment, most of them lack the flexibility of an open-source solution. There is a long-standing debate on the wisdom of retrofitting certain well-established equipment versus replacing it with more modern versions [75]. However, this retrofitting is mostly considered as a last resort to the equipment change, as typically a plant is designed keeping in mind for a period of about 20 years or more. Also, process variability demanding change in equipment or including parts of equipment is not feasible always keeping the economy in mind.

\section{Risk and safety assessment of control strategies}

The bioprocess sector is well versed in identifying the health concerns associated with biochemical processes, as well as implementing stringent quality control methods at all stages of production and processing. The biological agents and their products are strictly regulated to ensure the safety of the personnel engaged [76, 77]. For example, while making a perfusion media in a manufacturing facility, mishaps can happen in 3D drums in the form of impeller crashing into the drum causing it to crack resulting in the spillage of whole media, or during media filtration procedure if the filter pore sizes are not correctly known and the filtration system has not been connected properly. There is a possibility of splashing of media, and there could be huge health and economic repercussions. Measures to be adopted for preparedness and readiness from the perspective of the user 
handling the control system fall into two broad categories as described below:

1. Preventive safety assurance activities (PSAA) comprising safety planning categorization, testing and inspection programs, quality assurance, preventive maintenance, training, procedures, and human factors development, based on the ranking algorithm of safety significance of systems, structures, components, and human actions ( $\mathrm{SSCH})$.

2. Making regulatory decisions regarding authorized configuration modifications, developing technical specifications, and monitoring risk online.

The term criticality has a huge role to play in risk assessment and also the cumulative effect of criticality. The criticality and sum of the criticality of parameters in a process have advantages based on optimization based on risk and cost. It has been observed that rating a preventive activity based on criticality results in a lower total load in a preventive activity, while the risk is minimized or held constant.

RIF gives us an estimate of the corrective priorities and acceptable risk values that can be obtained when a process/ component is already known to be failing or when intending to take the component out of service for breakdown maintenance [78].

CPP is the critical process parameter whose variability has an impact on CQA and therefore should be monitored or controlled to ensure the process achieves the desired quality. KPA is used to measure the lack of process consistency, but does not affect product quality. It is synonymous with the process performance attribute. KPP can be regarded as an adjustable parameter that when maintained within a narrow range ensures optimum process performance. The ranges in KPP are adjusted during process development and changes to operating ranges are managed in quality systems. In short, these are some of the parameter classification norms that have been followed to generate the qualitative risk assessment protocol. A qualification called 'potential' to underscore the generic nature of the process has been used in the risk assessment flowchart which decides on parameters or attributes that could be important and require additional data to assign a critical rating.

A guideline for risk assessment has been described below (Fig. 2) which has been developed by Biophorum Operations Group Limited for parameter classification.
Fig. 2 Risk assessment guideline (Figure adapted from [79])

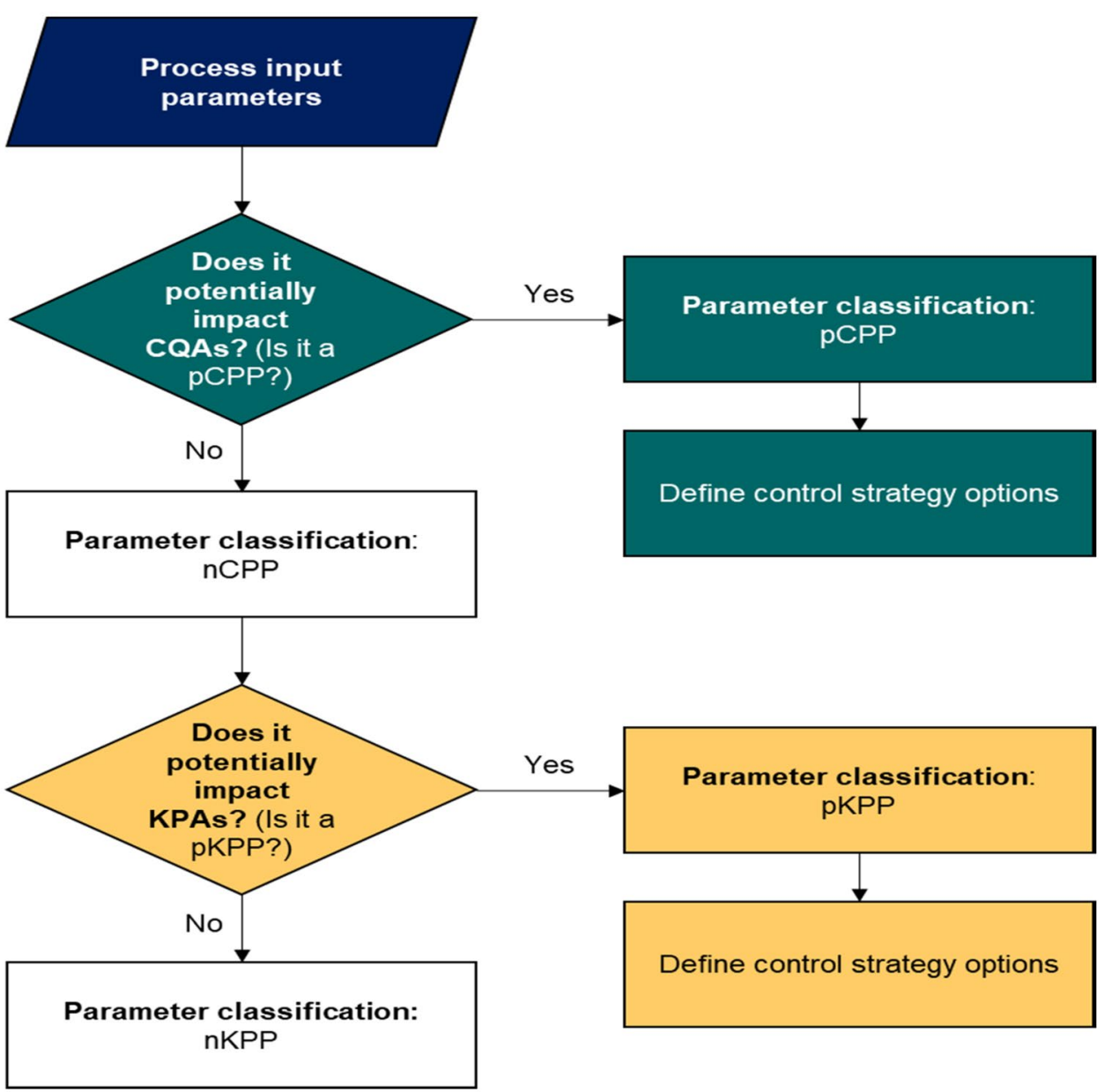




\section{Contamination control associated with control systems}

The introduction of multi-parametric sensors has been considered as a possible opportunity for reduced contamination and improved safety protocols, as a small number of openings will be required during the manufacturing process and also reduce the contact between the bioprocess and the environment [80]. Unpredictable risks for example rupturing of the bag, damage to sensors due to drift or delay, and power shutdown can be directly or indirectly be a possible source of contamination to the process concerned. In this type of situation, a backup should be in place on-site so that there is not much delay in resuming the process again without any interruption leading to possible damage or loss of product [81].

\section{Process analytical technology for quality assurance}

Maintenance or improvement of the product quality does require technologies like PAT, which strives to measure, analyze, monitor, and ultimately manage all critical qualities of a bioprocess [36, 82]. The PAT system incorporates a variety of operations that support the QbD strategy, ranging from the development and installation of unique analytical sensors for the measurement of certain specific solutions to risk management measures, and advanced data analysis methodologies. This spans a wide picture of the system that includes chemical, physical, and microbiological data that can be quantified. Dynamic models enable process systems engineering methodologies in PAT, which include design, understanding, optimization, monitoring, and control of production processes. Even though the PAT guidelines were designed for the pharmaceutical industry, many other life sciences sectors, including industrial biotechnology, which includes the food, feed, and biopharmaceutical industry, are adopting this approach.

PAT does offer the opportunity to control the process based on in-line/real-time measurements. Raman spectroscopy is one of the most widely used PAT due to its possibilities of usage in upstream biopharmaceutical industries. Monitoring and control of bioburden, endotoxins, and aggregates using PAT could contribute to the robustness of continuous biomanufacturing. Certain unique parameters like particle size distribution and filter impact using an inline particle size analyzer in conjunction with PAT can be implemented. Measurement of output concentrations based on critical parameter regulation can also be implemented using PAT as an additional level of control. So, all these instances culminate into the understanding of the fact that PAT can revolutionize the bioprocess industry, especially the biopharmaceutical domain.

\section{Economics and environmental impact assessment}

Economics and environmental impact assessment mostly includes integration of LCA, model analysis, water quality indicators for wastewater treatment plants, and distinctive impact categories [83, 84]. Many high-value-added manufacturing businesses, particularly specialized chemicals and pharmaceuticals, place a premium on batch end-product quality control $[85,86]$.

\section{Cost of control strategies}

Direct cost analysis and estimation based on various parameters such as stirring speed, gas requirement, medium to be used for cultivation, and cost of cooling can be done to determine the impact of different parameters on the overall process economics $[87,88]$. There is not much literature and studies available concerning the cost that is encountered while implementing a new process algorithm. The implementation cost is related to the number of loops and process loops involved in an APC; however, a functional dependency is difficult to derive. Hardware requirements and upgradation also are part of the new control architecture. Costs associated with production loss due to installation downtime are also a part of the development of control architecture. Miscellaneous costs could also be there due to failure or unmet needs that might have not been predicted from beforehand or a mishap during a run.

A differentiation between risk in cost and risk in benefit must be done. The two most important risk factors pertaining to cost are novelty and complexity. Both of them are intricately involved in the project's resource allocation. A newly developed technology can be implemented with little risk if the control engineers are experienced, knowledgeable, and fully devoted to the project while a proven application may fail if not enough or inexperienced staff members are involved.

\section{Environmental impact minimization through control strategies}

The environmental effects of bioprocess technologies have recently become a significant subject of concern. Many factors have fueled this interest, including concerns about climate change, pollution, and energy supplies; rapidly rising costs and waste disposal restrictions; a greater understanding of the status of disposables in bioprocessing; and the availability of a wider variety of disposable choices.

As a result, today's process designers and customers must be able to monitor and give information on the environmental consequences and sustainability of their manufacturing 
processes. This operation can be challenging and time-consuming, especially when dealing with multistage operations that use stainless steel equipment or disposable.

Before agreeing to proceed with a planned action, an environmental assessment examines the environmental implications of a proposal, strategy, program, or actual project. Prospective environmental footprints for the process's numerous discharge sources, as well as possible mitigations and their downsides, can be produced. Proposed technological advancements can also be assessed for their influence on the environment, with opposing and supporting effects established for various footprint areas [89].

Waste disposal constraints, water supply limits, energy prices, and other local issues would all play a role in any form of assessment. There are a variety of sources of information that can assist with an environmental assessment, including guidelines from industry associations, regulatory guidelines (e.g., BioProcess Systems Alliance, BPSA), directives, data from suppliers and manufacturers, written papers, reports, reviews, and case studies.

\section{Historical timeline and trends in bioprocess control}

Bioprocess model development covering more than one century of research and development in modeling, monitoring, control, and optimization concepts as well as high computation models and potential future trends in industrial bioprocess especially in the biopharmaceutical industry has been clearly demonstrated in (Fig. 3) given below [90].

The history pertaining to bioprocess control is vast and huge as it dates back to World War II. The development of discrete-time control theory began around that time, followed by the state-space theory which developed around 1950-1960s. It was demonstrated that the optimal-linear quadratic control problem can be reduced down to a certain Riccati equation. The stochastic theory simultaneously also started developing at that time. Automatic control problems having algebraic character were shown to have solutions that were obtained from polynomial methods. In the late 1960s, the idea of adaptive control also emerged, the development of which was influenced by the theory of dual control, parameter estimation, and recursive algorithms. The 1970s saw the rise of integrated control systems such as PLCs, DCSs, and SCADA as discussed earlier. Recent model developments include IMC (internal model control), MBPC (model-based predictive control), and EMPC (economic model predictive control) [91].

Post-digitization saw the rise of a hierarchical structure control system, which is basically a networked control system maintained as a hierarchy through links and these links are the computer systems that maintain a network. Technically, HSCS comprises two famous network systems-DCSs and PLCs. An alternative to HSCS is FCS which can be divided into two sections-field devices comprising sensors, actuators, and communication channels, and the second comprising the computer connections. For mobile communication technology and wireless communication, FCS

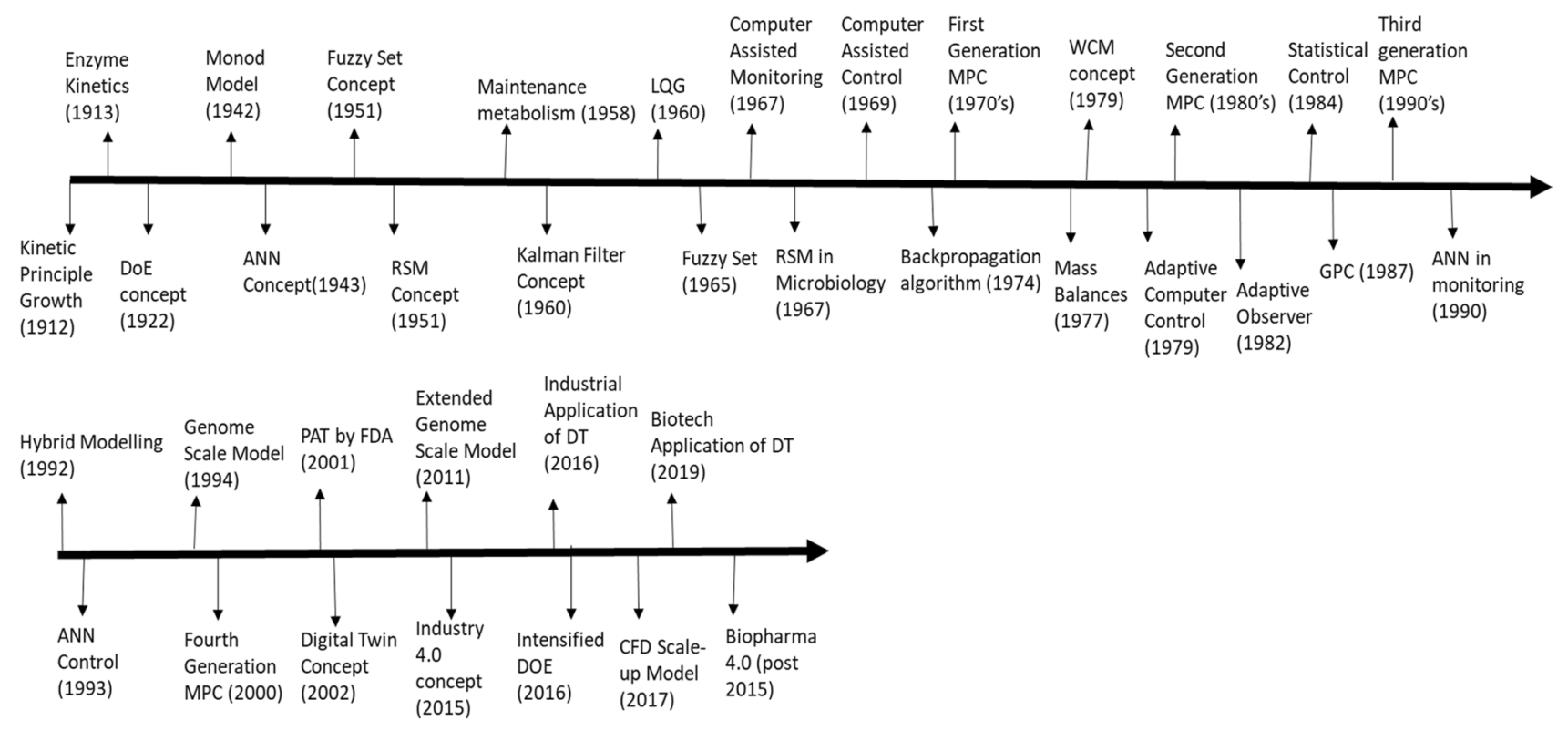

Fig. 3 Timeline of model concepts, monitoring, control, and optimization concepts and potential future trends in industrial bioprocess. ( Adapted from Noll et. al [90]) (For more information about individual technologies, please refer to SUPPLEMENTARY DATA 2) 
gets adopted in many industries. Followed by FCS came in the NCS, wherein all the field devices were connected using a network and using the Internet for data transmission instead of Fieldbus which is used in FCS. The core difference of NCS from FCS is that the hierarchical structure was fully replaced by a fully distributed structure, with each and every device connected to a network via node. The rise of both FCS and NCS did some really good work in bioreactor control; however with the emergence of PAT-integration of offline/online process datasets into a real-time control system became a problem. This gave rise to KBCS which took care of this issue and was implemented at two levels-the first level: direct control of a specific parameter using fuzzy logic and the second level entails a higher knowledge-based supervisory control system which consisted of modules such as knowledge base, database, and inference. KBCS proved to be hugely successful working in conjunction with various regulatory controls like PID [27].

\section{Market analysis and future trends}

Understanding the market scenario and stature of bioreactor control systems as of today is that more unique solutions come up with increased efficiency and control. Although PAT and QbD technologies are at play in the market, a sophisticated need is observed in MVDA requirement which is in literature regarded as future and enabler of PAT. From 2014 to 2020 , the advanced process control market is projected to develop at a CAGR of 11.79 percent. Extensive research has been observed on membrane bioreactors and single-use wave bioreactors over the past few years [92, 93].

Even though the economics of scale and scope has been subjected to a robust and dynamic environment in the last few years leading to some saying that there is the existence of no proper economic model as such when it comes to marketing of the product (e.g., vaccine and medicines), it is quite evident that the various commercialized process control schemes will definitely have successful long run irrespective of the type control scheme being used. The near future trends point to the increasing adoption of membrane technology, sensor technology, single-use bioreactor, and advanced control architectures. Also, cloud-based technology like Industry 4.0, Biopharma 4.0, and IIoT paves the way for an opportunity in the market for specialized control systems for producing specific products in the biopharmaceutical industry.

\section{Increased pharmaceutical drug production}

There is absolutely no doubt that both pharmaceutical and biopharmaceutical will have successful business ventures in terms of drug development given the current scenario. With regard to single-use biomanufacturing, a trend for developing small and efficient systems that are to be used in association with single-use bioreactors is expected to witness wide adoption in the next 5 years. The smaller companies especially in the domain of biopharmaceuticals increase their utilization of services of engineering, procurement, and construction companies (EPCs) so as to upgrade the bioreactor facility.

\section{Scalable/just in time vaccine production}

Traditionally, the production of vaccines and distribution used to take about 3 years with full-scale clinical trials, data generation, validation, documenting, and approval. However, the CoVID-19 pandemic has demonstrated the need and the ability of the biopharmaceutical industry to produce vaccines at much faster rates and shorter turnaround times as implemented in the USA in a program called 'Operation Warp Speed' [94]. Some of the key areas that should or can facilitate increased vaccine production are indicated in Fig. 4.

\section{Development of reliable supply chains}

Supply chains link together cross-department functionality with invariably dynamic integration of skilled, unskilled, and expert people in bringing about an environment of working together to deliver goods and services necessary for carrying out a process. Supply chain management with regard to the biopharmaceutical industry still requires a lot of coordination among raw material supplies and producers of API, with many layers of documentation and procedures for traceability and quality assurance [95]. Assuring the operation of reliable supply chains even in the face of natural

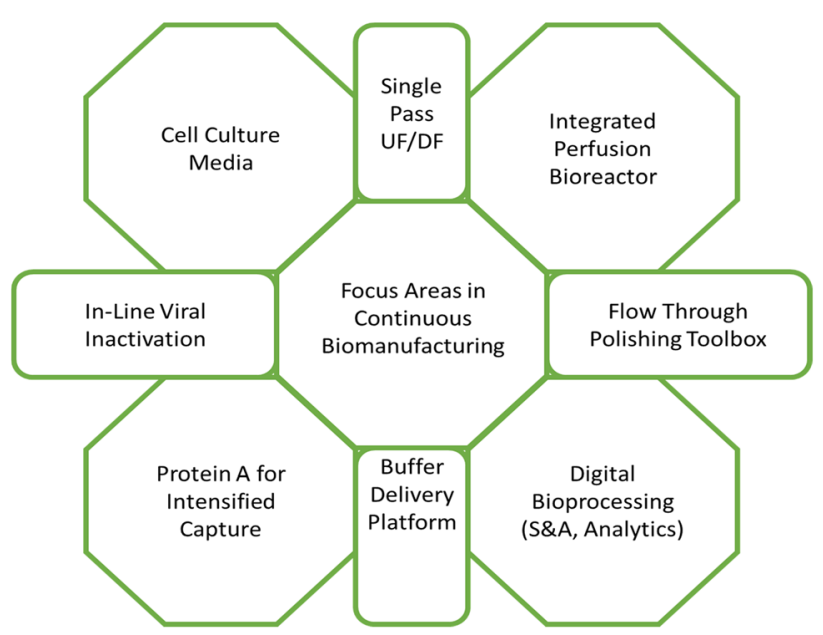

Fig. 4 Key areas concerning continuous biomanufacturing that needs to be critically assessed for efficient vaccine production 
Table 1 List of companies involved in single-use technology

\begin{tabular}{|c|c|}
\hline Company name & Product names \\
\hline ThermoFisher Scientific & $\begin{array}{l}\text { Bags, containers, connectors, filters, filling systems, sampling systems, tube welders, sensors, system } \\
\text { control, bioreactors } \\
\text { mixers, plates, flasks }\end{array}$ \\
\hline Gore & Sampling systems, tubing, valves, freeze and freeze-dry dishes \\
\hline Merck Millipore & $\begin{array}{l}\text { Bags, containers, connectors, filters, tubing, sampling systems, mixers, bioreactors, incubation shak- } \\
\text { ers for SUB, filling systems, platform solutions for USP and DSP }\end{array}$ \\
\hline Sartorius Stedim Biotech & $\begin{array}{l}\text { Bags, containers, connectors, filters, tubing, sampling systems, mixers, bioreactors, filling systems, } \\
\text { membrane adsorbers, freeze and thaw systems, platform solutions for USP and DSP, tube welders, } \\
\text { resealers }\end{array}$ \\
\hline Meissner & Bags, bioreactors, containers, mixers, and filters \\
\hline Terumo & Bags, tube welders, resealers \\
\hline Trace ANALYTICS GmbH & Sensors and sampling sytems \\
\hline GE Healthcare/Cytiva & $\begin{array}{l}\text { Bags, containers, connectors, filters, tubing, sampling systems, mixers, } \\
\text { bioreactors, filling systems, chromatography columns, tube welders, resealers }\end{array}$ \\
\hline Pall & Mixers, bags, bioreactors, connectors, filter, filling systems, platform solutions for USP and DSP \\
\hline JM Separations & Bags, tubing, manifolds, mixers, filters \\
\hline Scientific Industries Inc & Bioreactors \\
\hline Repligen & Chromatorgraphy \\
\hline Eppendorf & Bioreactors (New Brunswick) \\
\hline Pierre Guerin & Bioreactors \\
\hline Jobst Technologies & Sensors \\
\hline Corning Life Sciences & Bags and bioreactors \\
\hline PBS Biotech & Bioreactors \\
\hline Watson-Marlow Fluid Technology Group & Pumps, tubings and filters \\
\hline Entegris & Bags, mixers, and bioreactors \\
\hline Schulte bagtainer systems $\mathrm{GmbH}$ & Containers \\
\hline Saint-Gobain & Connectors, tubings \\
\hline Parker Hannifin Corp & sensors (SciLog) \\
\hline mp2-labs & Bioreactors \\
\hline Lonza & Containers \\
\hline Hamilton & Sensors (Fogale Biotech) \\
\hline CeLLution Biotech & Bioreactors \\
\hline ExcellGene & Bioreactors \\
\hline Ocean Optics & Sensors \\
\hline Machine Solutions Inc & Tube welders \\
\hline Dover Corp's Pump Solution group & Pumps \\
\hline Celltainer Biotech BV & Bioreactors \\
\hline Levitronix & Pumps \\
\hline PendoTECH & Sensors \\
\hline PreSens & Sensors \\
\hline Infors AG & Incubation shakers \\
\hline Gemue $\mathrm{GmbH}$ & Membrane valves \\
\hline Applikon & Bioreactors \\
\hline Adolf Kuhner AG & Incubation shakers for single-use bioreactors \\
\hline Cole-Parmer & Sensors \\
\hline C-Cit & Sensors \\
\hline Cellexus & Bioreactors \\
\hline Charter Medical & Bags \\
\hline Bosch Pharma & Dosing and filling systems \\
\hline Advantapure & Tubing \\
\hline ARTeSYN & Valves \\
\hline
\end{tabular}


Table 1 (continued)

\begin{tabular}{ll}
\hline Company name & Product names \\
\hline 3 M Purification & Filters \\
Aber Instruments & Sensors \\
AC Engineering & Pumps \\
\hline
\end{tabular}

disasters, pandemics and other disruptions with increased localization efforts around the world for APIs will be the leading trend soon.

\section{Increased single-use technologies}

The increased usage of disposables in the process industry has led to instigating the OEMs and EPCs to focus on the development of single-use manufacturing to broaden their portfolios. OEMs not only restrict themselves to equipment supply only, but also provide system integration services which include piping, instrumentation, and programming with built-in software that can work platform independently. Even though there is wide adoption and huge popularity of single use in the market, single-use bioreactors are still unable to replace stainless steel bioreactors, as SUBs are available in limited volume capacities. Market players are increasingly investing in research and development for overcoming the limited-volume capacities of SUBs by including and excluding additional features that might be customized for the process to be performed [96].

The following table (Table 1) gives the estimate of 48 companies, which are currently involved in single-use technology productions and how many products they produce.

\section{Decreased time from the laboratory to the field}

With regard to the biopharmaceutical industry, process optimization, intensification, and data analytics currently play a huge role in the advent of newer and efficient vaccines from continuous biomanufacturing practices. A typical example of a biopharmaceutical company adopting a flexible distributed control system is Gilead Sciences, which looks into the pilot-scale studies, research, and development, clinical trials, and meets pipeline demands as per customer requirements. Banks Integration partnered with Gilead Sciences to develop a control architecture that would be required for Phase III clinical trials and needed two glass-lined reactor suites and one corrosion-resistant steel reactor suite. Banks Integration addressed the needs of the Gilead Sciences which included less hardware-oriented and less programming, easy scalability, visibility, and flexibility consideratio ns for building the control system and thus developed accordingly [97].

\section{Need for scale-free control systems}

Scale-free control systems are those that can be deployed at multiple scales without modification of the core control strategies/algorithms. Experiments have been performed wherein scale-up procedures were performed with no tweaking or changing the original control architecture that was used for a low-scale process. There is a need for developing such systems, especially with the increased adoption of the SUBs by the biopharmaceutical industry.

\section{Conclusions}

There has been a thorough discussion on the different types of modeling, simulation, and computational structures available along with various requirements to develop different control architectures. Also, total plant-level automation levels have been intricately discussed with coming-of-age trends in things like IIoT and Biopharma 4.0. A discussion on historical and future trends in the development of bioreactor configurations and sensor technologies indicate increased use of single-use bioreactors with a much more sensor-intensive networked process control environment. The rise of the single-use technologies is aligned with the new paradigms Biopharma 4.0, leading to a shift toward 'total intensification' with minimal needs in terms of increased productivity, shortening timelines, reduced cost of goods, increased flexibility, and definitely reduced footprint. Such developments are needed for preparing humanity for the current and future challenges in healthcare to assure a healthy future for humanity.

Supplementary Information The online version contains supplementary material available at https://doi.org/10.1007/s43393-021-00048-6.

Acknowledgements Both the authors would also like to thank the Indian Institute of Technology, Indore, for providing the environment and necessary support in materializing this paper.

Author contributions SM: conceptualization, literature review, analysis, writing —original draft. GM: conceptualization, analysis, supervision, writing - review and editing. 


\section{Declarations}

Conflict of interest The authors have declared no conflict of interest and both of them have equal contributions.

\section{References}

1. Koutinas M, Kiparissides A, Pistikopoulos EN, Mantalaris A. Bioprocess systems engineering: transferring traditional process engineering principles to industrial biotechnology. Comput Struct Biotechnol J. 2012;3: e201210022. https://doi.org/10.5936/csbj. 201210022.

2. Sabra W, Dietz D, Tjahjasari D, Zeng AP. Biosystems analysis and engineering of microbial consortia for industrial biotechnology. Eng Life Sci. 2010;10:407-21. https://doi.org/10.1002/elsc.20100 0111.

3. Wang Y, Chu J, Zhuang Y, Wang Y, Xia J, Zhang S. Industrial bioprocess control and optimization in the context of systems biotechnology. Biotechnol Adv. 2009;27:989-95. https://doi.org/10. 1016/j.biotechadv.2009.05.022.

4. Pallavi S. Lesson introduction to industrial automation and control. 2013; 1-18

5. Zulkeflee SA, Aziz N, Campus E, Ampangan S, Tebal N. Control implementation in bioprocess system : a review. Int Conf Control Instrum Mechatron Eng. 2007; 798-804

6. Mandenius CF. Recent developments in the monitoring, modeling and control of biological production systems. Bioprocess Biosyst Eng. 2004;26:347-51. https://doi.org/10.1007/ s00449-004-0383-z.

7. Marwick JD, Wright PC, Burgess JG. Bioprocess intensification for production of novel marine bacterial antibiotics through bioreactor operation and design. Mar Biotechnol. 1999;1:495-507. https://doi.org/10.1007/PL00011806.

8. Murthy GS, Johnston DB, Rausch KD, Tumbleson ME, Singh V. Design and evaluation of an optimal controller for simultaneous saccharification and fermentation process. Appl Biochem Biotechnol. 2012;166:87-111. https://doi.org/10.1007/ s12010-011-9406-9.

9. Betts JI, Baganz F. Miniature bioreactors: current practices and future opportunities. Microb Cell Fact. 2006;5:1-14. https://doi. org/10.1186/1475-2859-5-21.

10. Bioreactors-an overview. ScienceDirect Topics. 2021. https:// www.sciencedirect.com/topics/neuroscience/biore actors. Accessed 28 May 2021

11. Murthy GS. Development of a controller for fermentation in the dry grind corn process. 2006

12. Selker M, Paldus B. Single-use solutions for scale-up and technology transfer. Innov Pharm Technol. 2009; 57-59

13. Mednis M, Meitalovs J, Vilums S, Vanags J, Galvanauskas V. Bioprocess monitoring and control using mobile devices. Inf Technol Control. 2010;39:195-201. https://doi.org/10.5755/j01.itc.39.3. 12369.

14. Rathore AS, Kateja N, Agarwal H. Part five continuous downstream bioprocessing. Contin Biomanufacturing Innov Technol Methods Innov Technol Methods. 2017; 261-279

15 Gomes J, Chopda V, Rathore AS. Monitoring and control of bioreactor: basic concepts and recent advances, bioprocess. Technol Prod Biopharm Bioprod. 2018. https://doi.org/10.1002/97811 19378341.ch6.

16. Knospe C. PID control. IEEE Control Syst. 2006;26:30-1. https:// doi.org/10.1109/MCS.2006.1580151.
17. Belhaj W, Boubaker O. On MIMO PID control of the quadrupletank process via ILMIs approaches: minimum and non-minimum case studies. IFAC Proc. 2013;46:481-6. https://doi.org/10.3182/ 20131218-3-IN-2045.00083.

18. Tatjewski P. Advanced control of industrial processes: structures and algorithms. 2007. http://www.springer.com/engineering/ control/book/978-0-85729-634-4\%0A. https://books.google.com/ books?hl=en\&lr=\&id=e_QEnZB0PLoC\&pgis $=1$.

19. Tang YJ, Heider R. Bridging the gap between academia and industry-Washington university's process control laboratories. In: Department of Energy, Environmental and Chemical Engineering at Washington University, St. Louis, MO 63130, United States, 2009; pp. 2730-2734. Doi: https://doi.org/10.1109/ACC. 2009.5160506.

20. Huusom JK. Control of bioprocesses. In: Fundam. Bioeng., Wiley Blackwell, Technical University of Denmark, Department of Chemical and Biochemical Engineering, Anker Engelunds Vej 1 Bygning 101A, Kgs Lyngby, 2800, Denmark. 2015; pp. 439-462. Doi: https://doi.org/10.1002/9783527697441.ch15.

21 Barker M, Rawtani J, Mackay S. Batch control technologies. Pract Batch Process Manag. 2005. https://doi.org/10.1016/b978-07506 6277-2/50011-6.

22. Lakerveld R, Benyahia B, Braatz RD, Barton PI. Model-based design of a plant-wide control strategy for a continuous pharmaceutical plant. AIChE J. 2013;59:3671-85. https://doi.org/10. 1002/aic.14107.

23 Hopkins D, St Amand M, Prior J. Bioreactor automation. Man Ind Microbiol Biotechnol. 2014. https://doi.org/10.1128/9781555816 827.ch51.

24. Faedo NE, Lucero M, Mazzone V, Suarez M, Rojas NL. Low cost SCADA for a laboratory-scale bioreactor, 2015 16th Work. Inf Process Control RPIC 2015. 2016. Doi: https://doi.org/10.1109/ RPIC.2015.7497090.

25. Prado-Rubio OA, Jørgensen SB, Jonsson G. Control system development for integrated bioreactor and membrane separation process. Amsterdam: Elsevier; 2010. https://doi.org/10.1016/S15707946(10)28049-5

26. Liljequist V. Development of a bioreactor simulator for supporting automation software test and verification. 2017. http://www. diva-portal.org/smash/get/diva2:1117825/FULLTEXT01.pdf.

27. Wang B, Wang Z, Chen T, Zhao X. Development of novel bioreactor control systems based on smart sensors and actuators. Front Bioeng Biotechnol. 2020;8:7. https://doi.org/10.3389/fbioe.2020. 00007.

28. Figueroa JL, Desages AC, Palazoglu A, Romagnoli JA, Romagnoli JA. Trade-offs in robust controller design. Int J Control. 1993;58:1265-78. https://doi.org/10.1080/00207179308923054.

29. Harris I. Animal cell culture. 1993. Doi: https://doi.org/10.1016/ 0307-4412(93)90121-f

30. Moysis L, Kafetzis I, Iliadou M, Tsiaousis M, Charalampidis N. An introduction to control theory applications with matlab. 2015. Doi: https://doi.org/10.13140/RG.2.1.3926.8243

31. Shimizu K. An overview on the control system design of bioreactors. Meas Control. 1993;50:65-84. https://doi.org/10.1007/bfb00 07387.

32. Hitit ZY, Ozyurt B, Ertunc S. The application of system identification and advanced process control to improve fermentation process of baker's yeast. Yeast Ind Appl. 2017. https://doi.org/10. 5772/intechopen.70696.

33. Konde KS, Modak JM. Optimization of bioreactor using metabolic control analysis approach. Biotechnol Prog. 2007;23:370 80. https://doi.org/10.1021/bp0602911.

34. Femat R. Control in bioprocessing : modelling, estimation and the use of soft sensors. Hoboken: Wiley; 2019. p. 2-4. 
35 Mesquita TJB, Sargo CR, Fuzer JR, Paredes SAH, Giordano RDC, Horta ACL, Zangirolami TC. Metabolic fluxes-oriented control of bioreactors: a novel approach to tune micro-aeration and substrate feeding in fermentations. Microb Cell Fact. 2019. https://doi.org/ 10.1186/s12934-019-1198-6.

36 Kornecki M, Strube J. Process analytical technology for advanced process control in biologics manufacturing with the aid of macroscopic kinetic modeling. Bioengineering. 2018. https://doi.org/10.3390/bioengineering5010025.

37. Clarke DJ, Blake-Coleman BC, Calder MR, Carr RJG, Moody SC. Sensors for bioreactor monitoring and control-a perspective. J Biotechnol. 1984;1:135-58. https://doi.org/10.1016/ 0168-1656(84)90001-4.

38. Hanafi R, Mayasari RD, Masmui A, Raharjo J, Nuryadi R. Electrochemical sensor for environmental monitoring system: a review. AIP Conf Proc. 2019; p. 2169. Doi: https://doi.org/10. $1063 / 1.5132657$

39. Busse C, Biechele P, de Vries I, Reardon KF, Solle D, Scheper T. Sensors for disposable bioreactors. Eng Life Sci. 2017;17:940-52. https://doi.org/10.1002/elsc.201700049.

40. Marose S, Lindemann C, Ulber R, Scheper T. Optical sensor systems for bioprocess monitoring. Trends Biotechnol. 1999;17:30-4. https://doi.org/10.1016/S0167-7799(98)01247-5.

41. Lourenço ND, Lopes JA, Almeida CF, Sarraguça MC, Pinheiro HM. Bioreactor monitoring with spectroscopy and chemometrics: a review. Anal Bioanal Chem. 2012;404:1211-37. https:// doi.org/10.1007/s00216-012-6073-9.

42. Shioya S, Shimizu K, Yoshida T. Knowledge-based design and operation of bioprocess systems. J Biosci Bioeng. 1999;87:2616. https://doi.org/10.1016/S1389-1723(99)80029-2.

43. Duysens LNM, Amesz J. Fluorescence spectrophotometry of reduced phosphopyridine nucleotide in intact cells in the nearultraviolet and visible region. BBA Biochim Biophys Acta. 1957;24:19-26. https://doi.org/10.1016/0006-3002(57)90141-5.

44. Kong D, Gentz R, Zhang J. Development of a versatile computer integrated control system for bioprocess controls. Cytotechnology. 1998;26:227-36. https://doi.org/10.1023/A:1007948313 304.

45. Kusterer A, Krause C, Kaufmann K, Arnold M, Weuster-Botz D. Fully automated single-use stirred-tank bioreactors for parallel microbial cultivations. Bioprocess Biosyst Eng. 2008;31:207-15. https://doi.org/10.1007/s00449-007-0195-Z.

46. Gogate PR, Beenackers AACM, Pandit AB. Multiple-impeller systems with a special emphasis on bioreactors: a critical review. Biochem Eng J. 2000;6:109-44. https://doi.org/10.1016/S1369703X(00)00081-4.

47 Chen X, Hu R, Hu L, Huang Y, Shi W, Wei Q, Li Z. Portable analytical techniques for monitoring volatile organic chemicals in biomanufacturing processes: recent advances and limitations. Front Chem. 2020. https://doi.org/10.3389/fchem.2020.00837.

48. Brooks SL, Turner APF. Biosensors for measurement and control. Meas Control. 1987;20:37-43. https://doi.org/10.1177/00202 9408702000401

49. O’Mara P, Farrell A, Bones J, Twomey K. Staying alive! Sensors used for monitoring cell health in bioreactors. Talanta. 2018;176:130-9. https://doi.org/10.1016/j.talanta.2017.07.088.

50. Luttmann R, Bracewell DG, Cornelissen G, Gernaey KV, Glassey J, Hass VC, Kaiser C, Preusse C, Striedner G, Mandenius CF. Soft sensors in bioprocessing: a status report and recommendations. Biotechnol J. 2012;7:1040-8. https://doi.org/10.1002/biot.20110 0506.

51 Satya Eswari J, Venkateswarlu C. Dynamic modeling and metabolic flux analysis for optimized production of rhamnolipids. Chem Eng Commun. 2016;203:326-38. https://doi.org/10.1080/ 00986445.2014 .996638 .
52 Pertev C, Türker M, Berber R. Dynamic modeling, sensitivity analysis and parameter estimation of industrial yeast fermenters. Comput Chem Eng. 1997. https://doi.org/10.1016/s0098-1354(97) 87591-6.

53 Rosa LFM, Hunger S, Zschernitz T, Strehlitz B, Harnisch F. Integrating electrochemistry into bioreactors: effect of the upgrade kit on mass transfer, mixing time and sterilizability. Front Energy Res. 2019. https://doi.org/10.3389/fenrg.2019.00098.

54 Galvanauskas V, Simutis R, Levišauskas D, Urniežius R. Practical solutions for specific growth rate control systems in industrial bioreactors. Processes. 2019. https://doi.org/10.3390/pr7100693.

55. Sarkar D, Modak JM. Optimisation of fed-batch bioreactors using genetic algorithms. Chem Eng Sci. 2003;58:2283-96. https://doi. org/10.1016/S0009-2509(03)00095-2.

56. Rani KY, Rao VSR. Control of fermenters-a review. Bioprocess Eng. 1999;21:77-88. https://doi.org/10.1007/s004490050644.

57. Zhong JJ. Recent advances in bioreactor engineering. Korean J Chem Eng. 2010;27:1035-41. https://doi.org/10.1007/ s11814-010-0277-5.

58. Ashok A, Doriya K, Rao DRM, Kumar DS. Design of solid state bioreactor for industrial applications: an overview to conventional bioreactors. Biocatal Agric Biotechnol. 2017;9:11-8. https://doi. org/10.1016/j.bcab.2016.10.014.

59. Mitchell DA, Krieger N, Berovič M. Solid-state fermentation bioreactors: fundamentals of design and operation, Springer Berlin Heidelberg, Federal University of Paraná, Department of Biochemistry and Molecular Biology, P.O. Box 19046, 81531-990 Curitiba-PR, Brazil. 2006. Doi: https://doi.org/10. 1007/3-540-31286-2

60. Stone KA, Hilliard MV, He QP, Wang J. A mini review on bioreactor configurations and gas transfer enhancements for biochemical methane conversion. Biochem Eng J. 2017;128:83-92. https:// doi.org/10.1016/j.bej.2017.09.003.

61. Gianetto A, Specchia V. Trickle-bed reactors: state of art and perspectives. Chem Eng Sci. 1992;47:3197-213. https://doi.org/10. 1016/0009-2509(92)85029-B.

62. Prado RC, Borges ER. Microbioreactors as engineering tools for bioprocess development. Braz J Chem Eng. 2018;35:1163-82. https://doi.org/10.1590/0104-6632.20180354s20170433.

63. Maharbiz MM, Holtz WJ, Howe RT, Keasling JD. Microbioreactor arrays with parametric control for high-throughput experimentation. Biotechnol Bioeng. 2004;85:376-81. https://doi.org/ 10.1002/bit.10835.

64. Kostov Y, Harms P, Randers-Eichhorn L, Rao G. Low-cost microbioreactor for high-throughput bioprocessing. Biotechnol Bioeng. 2001;72:346-52. https://doi.org/10.1002/1097-0290(20010205) 72:3\%3c346::AID-BIT12\%3e3.0.CO;2-X.

65. Hong MS, Braatz RD. Mechanistic modeling and parameteradaptive nonlinear model predictive control of a microbioreactor. Food Pharm Bioeng Div 2018-Core Program. Area 2018 AIChE Annu Meet. 2018; 2: 918-920. Doi: https://doi.org/10. 1016/j.compchemeng.2021.107255

66. Junne S, Neubauer P. How scalable and suitable are single-use bioreactors? Curr Opin Biotechnol. 2018;53:240-7. https://doi. org/10.1016/j.copbio.2018.04.003.

67. Alford JS. Bioprocess control: advances and challenges. Comput Chem Eng. 2006;30:1464-75. https://doi.org/10.1016/j.compc hemeng.2006.05.039.

68. Ouano EAR. Oxygen mass transfer scale up in rotating biological filters. Water Res. 1978;12:1005-8. https://doi.org/10.1016/00431354(78)90083-0.

69 Abraham E, Gupta S, Jung S, McAfee E. Bioreactor for scale-up: process control. Amsterdam: Elsevier Inc.; 2017. https://doi.org/ 10.1016/b978-0-12-802826-1.00006-4.

70. Xia J, Wang G, Lin J, Wang Y, Chu J, Zhuang Y, Zhang S. Advances and practices of bioprocess scale-up. Adv Biochem 
Eng Biotechnol. 2016;152:137-51. https://doi.org/10.1007/10_ 2014_293.

71. Garcia-Ochoa F, Gomez E. Bioreactor scale-up and oxygen transfer rate in microbial processes: an overview. Biotechnol Adv. 2009;27:153-76. https://doi.org/10.1016/j.biotechadv.2008.10. 006.

72. Moucha T, Rejl FJ, Kordač M, Labík L. Mass transfer characteristics of multiple-impeller fermenters for their design and scaleup. Biochem Eng J. 2012;69:17-27. https://doi.org/10.1016/j.bej. 2012.08.007.

73. Kuhn D, Blank LM, Schmid A, Bühler B. Systems biotechnology - rational whole-cell biocatalyst and bioprocess design. Eng Life Sci. 2010;10:384-97. https://doi.org/10.1002/elsc.20100 0009.

74. Ranjan AP, Gomes J. Simultaneous dissolved oxygen and glucose regulation in fed-batch methionine production using decoupled input-output linearizing control. J Process Control. 2009;19:66477. https://doi.org/10.1016/j.jprocont.2008.07.008.

75. Peuker T, Bogner A. Equipment design and facility layout for flexible biomanufacturing processes. Eng Life Sci. 2011;11:443-51. https://doi.org/10.1002/elsc.201000174.

76 Spann R, Lantz AE, Gernaey KV, Sin G, Lyngby K. Modeling for process risk assessment in industrial bioprocesses. Amsterdam: Elsevier Inc.; 2018. https://doi.org/10.1016/B978-0-12-409547-2. 14356-2.

77 Okhio-Seaman L. Validation, quality, and regulatory considerations in continuous biomanufacturing. Contin Biomanufacturing Innov Technol Methods. 2017. https://doi.org/10.1002/97835 27699902.ch20.

78. Vaurio JK. Importance measures in risk-informed decision making: ranking, optimisation and configuration control. Reliab Eng Syst Saf. 2011;96:1426-36. https://doi.org/10.1016/j.ress.2011. 06.012 .

79. Biophorum. A risk-based blueprint for process control of continuous bioprocessing : phase 1 : generic risk assessment and process control parameters. 2021

80. Biopharmaceutical quality optimization. 2016

81. Larroche C, Sanromán MA, Du G, Pandey A. Current developments in biotechnology and bioengineering: bioprocesses bioreactors and controls. Amsterdam: Elsevier; 2016.

82. Jenzsch M, Simutis R, Lübbert A. Optimization and control of industrial microbial cultivation processes. Eng Life Sci. 2006;6:117-24. https://doi.org/10.1002/elsc.200620901.

83. An Environmental Lifecycle Assessment of Single-Use and Conventional Process Technology: Comprehensive Environmental Impacts. 2021. https://www.biopharminternational.com/view/ environmental-lifecycle-assessment-single-use-and-convention al-process-technology-comprehensive-envi. Accessed 29 May 2021

84. Ferrero G, Rodríguez-Roda I, Comas J. Automatic control systems for submerged membrane bioreactors: a state-of-the-art review. Water Res. 2012;46:3421-33. https://doi.org/10.1016/j.watres. 2012.03.055
85. Wan J, Marjanovic O, Lennox B. Disturbance rejection for the control of batch end-product quality using latent variable models. J Process Control. 2012;22:643-52. https://doi.org/10.1016/j.jproc ont.2011.12.012.

86. Albertos P, Garcia P, Gao Z, Liu T. Disturbance rejection in process control. Proc World Congr Intell Control Autom. 2015. https://doi.org/10.1109/WCICA.2014.7053408.

87. Harrison RG, Todd PW, Rudge SR, Petrides DP. Bioprocess design and economics. Oxford: Oxford University Press; 2015. https://doi.org/10.1093/oso/9780195391817.003.0015.

88. Cardoso VM, Campani G, Santos MP, Silva GG, Pires MC, Gonçalves VM, de Giordano RC, Sargo CR, Horta ACL, Zangirolami TC. Cost analysis based on bioreactor cultivation conditions: Production of a soluble recombinant protein using Escherichia coli BL21(DE3). Biotechnol Rep. 2020. https://doi.org/10.1016/j.btre. 2020.e00441.

89. Minimizing the Environmental Footprint of Bioprocesses-BioProcess InternationalBioProcess International. 2021. https://biopr ocessintl.com/manufacturing/facility-design-engineering/minim izing-the-environmental-footprint-of-bioprocesses-303905/. Accessed 29 May 2021

90. Noll P, Henkel M. History and evolution of modeling in biotechnology: modeling and simulation, application and hardware performance. Comput Struct Biotechnol J. 2020;18:3309-23. https:// doi.org/10.1016/j.csbj.2020.10.018.

91. Camacho EF, Alba CB. Model predictive control (google ebook). 2013; p, 427. http://books.google.com/books?hl=en\&lr=\&id= tXZDAAAAQBAJ\&pgis $=1$.

92. Major Players Operating in the Global Bioreactors Market 20192023. Technavio. Business Wire. 2021. https://www.businesswire. com/news/home/20190726005097/en/Major-Players-OperatingGlobal-Bioreactors-Market-2019-2023/?feedref=JjAwJuNHiy stnCoBq_hl-f-Mqy7--9RYfS_LXgrtWW7rOkYSjTKorE14c7uw cjIHj_R0p0VFN6GsXdq8PYoIcFEYGffXvFUnUBNNmxNkJd nQqLx557vS7ZRxiEolcr-hHrZo_gzQzmbSVgCo2ySDfw\%3D\% 3D. Accessed 29 May 2021

93. Bioreactors Market Growth Analysis. Global Forecast Report 2027. 2021. https://www.gminsights.com/industry-analysis/biore actor-market. Accessed 29 May 2021

94. Coronavirus: Operation Warp Speed. 2021. https://www.defen se.gov/Explore/Spotlight/Coronavirus/Operation-Warp-Speed/. Accessed 17 July 2021

95. Olson DL, Swenseth SR. Trade-offs in supply chain system risk mitigation. Syst Res Behav Sci. 2014;31:565-79. https://doi.org/ 10.1002/sres.2299.

96. Download PDF Brochure-Bioreactors Market. Growing at a CAGR of $6.8 \%$. MarketsandMarkets. 2021. https://www.marke tsandmarkets.com/pdfdownloadNew.asp?id=59253123. Accessed 29 May 2021

97. Control Engineering. Biopharmaceutical company optimizes manufacturing processes with modern DCS. 2021. https://www.contr oleng.com/articles/biopharmaceutical-company-optimizes-manuf acturing-processes-with-modern-dcs/. Accessed 2 July 2021 